\title{
Generalizability of cardiovascular reactivity to stress among doctoral students between laboratory and natural settings
}

James P. Davig

West Virginia University

Follow this and additional works at: https://researchrepository.wvu.edu/etd

\section{Recommended Citation}

Davig, James P., "Generalizability of cardiovascular reactivity to stress among doctoral students between laboratory and natural settings" (1999). Graduate Theses, Dissertations, and Problem Reports. 3126.

https://researchrepository.wvu.edu/etd/3126

This Dissertation is protected by copyright and/or related rights. It has been brought to you by the The Research Repository @ WVU with permission from the rights-holder(s). You are free to use this Dissertation in any way that is permitted by the copyright and related rights legislation that applies to your use. For other uses you must obtain permission from the rights-holder(s) directly, unless additional rights are indicated by a Creative Commons license in the record and/ or on the work itself. This Dissertation has been accepted for inclusion in WVU Graduate Theses, Dissertations, and Problem Reports collection by an authorized administrator of The Research Repository @ WVU.

For more information, please contact researchrepository@mail.wvu.edu. 


\title{
GENERALIZABILITY OF CARDIOVASCULAR REACTIVITY \\ TO STRESS AMONG DOCTORAL STUDENTS \\ BETWEEN LABORATORY AND NATURAL SETTINGS
}

James P. Davig, Ph.D.

\author{
A Dissertation submitted to the \\ College of Arts and Sciences \\ at West Virginia University \\ in partial fulfillment of the requirements \\ for the degree of \\ Doctor of Philosophy \\ in \\ Clinical Psychology
}

Kevin T. Larkin, Ph.D., Chair

Barry Edelstein, Ph.D.

Alfred L. Kasprowicz, Ph.D.

Stanley Cohen, Ph.D.

LauraLee Sherwood, D.V.M.

Department of Psychology

Morgantown, West Virginia

1999

Keywords: Cardiovascular Reactivity, Ambulatory Monitoring, Generalizability, Reliability

Copyright 1999, James P. Davig 


\begin{abstract}
GENERALIZABILITY OF CARDIOVASCULAR REACTIVITY TO STRESS AMONG DOCTORAL STUDENTS BETWEEN LABORATORY AND NATURAL SETTINGS

James P. Davig
\end{abstract}

This study extends previous work investigating the generalizability of cardiovascular reactivity to stress obtained in response to laboratory-based tasks to cardiovascular reactivity measured in response to a natural occurring event. Cardiovascular reactivity (HR,SBP,DBP) to stress was measured with ambulatory monitoring equipment in 6 male and 16 female healthy Caucasian graduate students in two settings: during five standardized laboratory stressors, and during the proposal or defense of a thesis or dissertation. Results indicate that for all cardiovascular parameters, the magnitude of change was greatest in response to the natural event, and that among the laboratory tasks, the greatest degree of reactivity was observed in response to the speech task. However, the cardiovascular reactivity associated with the speech task was not the best predictor of the natural speech task, despite the structural similarity of these two tasks. Overall, greater correlations were noted among all of the tasks based on absolute values of HR and $\mathrm{BP}$ versus residualized change scores for $\mathrm{HR}$ and $\mathrm{BP}$, and greater correlations were also observed among anticipation periods than among task periods. Partial support was provided for the hypothesis that the generalizability of cardiovascular reactivity to stress would be enhanced using an aggregation of multiple tasks rather than single tasks. This effect was observed for HR but not BP. Consistent with the literature in this field, only limited generalizability of cardiovascular response to stress was observed.

Generous financial support was provided by the West Virginia University Department of Psychology Alumni Fund as well as the Office of Academic Affairs and Research. 


\section{Acknowledgements}

Without Kevin's guidance, support, and expertise, this project would not have succeeded. Words cannot convey my appreciation for both the assistance he has provided, and the excellent clinical, academic, and personal example he has provided for me. Also instrumental in this project has been the assistance of Jeff Goodie; I don't know what I would've done without you. Sincere thanks also to the members of my committee, all of whom truly added to the substance and quality of the final product. Graduate school would be a much more tolerable experience if all students were surrounded by such support.

Finally, this experience has imprinted on me the importance of emotional support. Friends and mentors who sustained me throughout graduate school deserve mention; in addition to those listed above, special thanks to Scott Schauss, Lynda Szymanski, Rick Seime, Virginia Goetsch, and Leslie and Susan Dozsa. Thank you to my extended family for all of the trips you made to visit us. Most importantly, thank you to my wife, Kris, and children, Grace and Peter, for keeping me sane. It could not have been an easy job. Also, thanks Knute. 


\section{TABLE OF CONTENTS}

$\begin{array}{ll}\text { Introduction } & 1\end{array}$

Cardiovascular Reactivity to Stress and Cardiovascular Disease 3

Cardiovascular Reactivity as a Stable Individual Difference Variable $\quad 6$

$\begin{array}{ll}\text { Temporal Stability } & 7\end{array}$

Cross-Task Reliability 9

Laboratory to Field Generalization 16

$\begin{array}{ll}\text { Statement of the Problem } & 21\end{array}$

$\begin{array}{ll}\text { Hypotheses } & 24\end{array}$

$\begin{array}{ll}\text { Method } & 25\end{array}$

$\begin{array}{ll}\text { Participants } & 25\end{array}$

$\begin{array}{ll}\text { Experimental Challenges } & 26\end{array}$

$\begin{array}{ll}\text { Cardiovascular Assessment } & 28\end{array}$

$\begin{array}{ll}\text { Procedure } & 28\end{array}$

Laboratory Assessment $\quad 29$

Ambulatory Assessment $\quad 29$

Data Reduction $\quad 30$

$\begin{array}{ll}\text { Results } & 30\end{array}$

Cardiovascular Parameters During Rest, Anticipation, and Task Periods $\quad 30$

Comparison of Task Reactivity Scores 35

Correlation Among Anticipation Periods and Task Periods 37 
Effect of Aggregation of Measures of Cardiovascular Reactivity on

Predicting Cardiovascular Reactivity to the Natural Setting 46

$\begin{array}{ll}\text { Intraclass Correlational Analyses } & 48\end{array}$

$\begin{array}{ll}\text { Discussion } & 50\end{array}$

$\begin{array}{ll}\text { Overview } & 50\end{array}$

Cardiovascular Response Differences Across Tasks $\quad 51$

Relations Between Laboratory Tasks and the Natural Setting 53

Aggregation of Laboratory Tasks and Natural Task Cardiovascular Response $\quad 55$

$\begin{array}{ll}\text { Limitations of the Study } & 58\end{array}$

$\begin{array}{ll}\text { Future Directions } & 62\end{array}$

$\begin{array}{ll}\text { References } & 66\end{array}$

$\begin{array}{ll}\text { Appendices } & 79\end{array}$

$\begin{array}{ll}\text { Vitae } & 88\end{array}$ 


\section{Introduction}

Since the 1930's, the leading cause of death in the United States has been cardiovascular disease (CVD), which includes the diagnoses of coronary artery disease and stroke (Jenkins, 1988). Although research has indicated a decrease in CVD mortality since the late 1960's (Levy $\&$ Kannel, 1988), it remains the number one cause of death in this country. According to the American Heart Association (1989), each year approximately 1.5 million Americans suffer a first or recurrent myocardial infarction, and over 500,000 die from this disease. In addition, the estimated national annual expenditure for medical bills and lost productivity and wages attributed to CVD is over 40 billion dollars.

The high frequency with which CVD occurs, along with the associated personal, medical, and social costs related to its treatment has resulted in vast amounts of research attempting to identify factors associated with increased risk of developing CVD. To this point, several undisputed factors have been determined, including: high total blood cholesterol, smoking, high blood pressure (especially diastolic pressure), increasing age, male gender, low high-density lipoprotein (HDL, or "good cholesterol"), obesity, physical inactivity, and diabetes mellitus (Scheidt, 1996). The first three of these, elevated serum cholesterol, smoking, and high blood pressure, have shown the strongest and most consistent association with CVD (Kannel, 1986; Levy \& Kannel, 1988). Risk factors currently considered controversial include: elevated blood triglycerides, Type A behavior, and other psychosocial attributes such as stress, social isolation, and depression (Scheidt, 1996). Although the use of such factors has improved the ability to predict CVD (Pooling Project Research Group, 1978), the combined use of these three biological risk factors accounts for only approximately $50 \%$ of the variance in predicting the development of 
coronary heart disease (Brand, Rosenman, Sholtz, \& Friedman, 1976; Jenkins, 1983). As such, some individuals with high risk factors do not develop CVD, while others with low or no risk profile will develop CVD (Steptoe, 1981).

Efforts to improve the prediction of CVD, and thus the opportunity to invoke preventive health habits and/or medical treatment, have also included investigation of behavioral factors that are related to the biological risk factors. For example, it has been shown that blood pressure and serum cholesterol levels may be elevated in association with a sedentary lifestyle and poor dietary habits (Jeffrey, 1988; Jenkins, 1988). A primary advantage of identifying causal behavioral factors is that once such etiologic relations are demonstrated, behavioral modification programs can be designed to eliminate or lower disease risk. By modifying lifestyle habits, individuals have demonstrated the ability to decrease total cholesterol levels (Blackburn \& Jacobs, 1984), improve the ratio of low density lipoproteins to high density lipoproteins (Blumenthal, Williams, Williams, \& Wallace, 1980; Jenkins, 1988), modify blood pressure levels via weight loss and decreased sodium intake (Jeffrey, 1988), and successfully discontinue smoking (Schwartz, 1987).

Perhaps the behavioral factor receiving the greatest amount of attention has been the Type A behavior pattern, originally proposed by Friedman and Rosenhan in 1959, which was based on their observations of cardiac patients. In sum, this pattern of behavior is exemplified by competitiveness, chronic time urgency, and underlying hostility (Friedman \& Rosenhan, 1959). Although early studies provided initial confirmation of an association between such behavior and subsequent coronary heart disease (e.g., Haynes, Feinleib, \& Kannel, 1980; Rosenman et al., 1975), more recent work has not demonstrated such a relation (e.g., Shekelle, Gale, \& Norusis, 1985).

Subsequent efforts focusing on the relation between specific aspects of Type A behavior and CVD have been more fruitful. For example, several studies have found associations between 
measures of hostility and risk for CVD but not between other components of Type A behavior pattern and CVD, including competitiveness and time urgency (Barefoot, Dahlstrom, \& Williams, 1983; Krantz, Contrada, Hill, \& Friedler, 1988). In addition, Dembroski and Costa (1988) demonstrated a strong association between hostility and CVD, though no association emerged between the global Type A pattern and CVD.

Although the above behavioral risk factors (i.e., Type A Behavior Pattern, hostility) have provided promising additions to the ability to predict CVD, the mechanisms by which these factors affect increased risk for CVD are not well known. One hypothesis addressing the link between behavioral factors and CVD is based upon the observation that people vary significantly in their degree of autonomic responsivity to behavioral stimuli and, accordingly, persons with exaggerated cardiovascular responses are predicted to exhibit the greatest risk for CVD.

\section{Cardiovascular Reactivity to Stress and Cardiovascular Disease}

The principle of "symptom specificity" (Malmo, Shagrass, \& Davis, 1950) hypothesized that individuals respond to stress most noticeably in a specific organ system that then predisposes them to symptomatic expressions of disease. For example, persons with the greatest risk for CVD were hypothesized to show a greater cardiovascular response to stress than persons at low risk for CVD. Though first articulated 45 years ago, the impact of this hypothesis has been most apparent in current work investigating CVD. In a summary of this literature, Manuck, Kasprowicz, Monroe, Larkin, and Kaplan (1989) recently provided support for the continued specific investigation into the relation between cardiovascular response to stress and CVD:

It is widely thought that the exaggerated physiologic responses to psychological challenge, or stress, may be implicated in the etiology or clinical expression of certain cardiovascular disorders, including coronary heart disease and essential hypertension. (p. 365) 
Cardiovascular reactivity to stress has been defined as an individual's propensity to experience cardiovascular reactions of a given magnitude, in relation to those of other persons, when encountering behavioral stimuli experienced as engaging, challenging, or aversive (Manuck, Kasprowicz, Monroe, Larkin, \& Kaplan, 1989). These stimuli can include psychomotor, cognitive, and interpersonal challenges frequently employed in laboratory-based research and their various analogues occurring in daily life. Cardiovascular reactivity to stress is usually operationalized as the arithmetic difference between heart rate and/or blood pressure measurements obtained during exposure to an eliciting stimulus and preceding baseline measurements, and has been proposed as one variable that may mediate the relation between behavioral characteristics and cardiovascular disease.

Although the exact causal pathways have not yet been extricated, research has demonstrated associations between exaggerated cardiovascular reactivity to stress and the development of coronary artery disease, hypertension, and the extent of atherosclerotic lesions (Krantz et al., 1988). Research supporting the reactivity hypothesis includes prospective investigations demonstrating an association between diastolic blood pressure reactivity to a cold pressor challenge and subsequent CVD (Keys et al., 1971) and essential hypertension (Wood, Sheps, Elveback, \& Schirger, 1984), and retrospective studies demonstrating greater blood pressure reactivity to stress among persons with coronary heart disease in comparison to healthy peers (e.g., Corse, Manuck, Cantwell, Giordani, \& Matthews, 1982; Sime, Buell, \& Elliot, 1980). Laboratory analog studies employing cynomolgus monkeys have provided further evidence of the association between cardiovascular reactivity to stress and CVD. For example, Manuck, Kaplan, \& Clarkson (1983) found that monkeys designated as "high reactive," based on their heart rate response to a standard "threat of capture" stressor, developed more than twice the 
amount of coronary artery atherosclerosis as low heart rate responsive animals.

Indirect evidence also provides some support for the relation between cardiovascular reactivity to stress and CVD. For example, Manuck, Morrison, Bellack, \& Polefrone (1985) found that adult males identified as demonstrating "high anger" exhibited greater HR responses to a mental arithmetic challenge than "low anger" peers. Further, Holroyd and Gorkin (1983) found that individuals who were self-described as tending to not express their anger (i.e., "anger-in") exhibited greater HR responses than those self-described as tending to readily express their anger (i.e., "anger-out"). Because of the hypothesized relation between hostility and CVD, these findings further support the importance of the role of cardiovascular response to stress in the pathogenesis of CVD.

In addition to the putative role of anger, individuals with a family history of hypertension also exhibit increased cardiovascular reactivity to stress in contrast to individuals of normotensive parents. For example, Manuck et al. (1985) found heightened cardiovascular reactivity to mental stressors among normotensive adults with hypertensive parents relative to normotensive adults with normotensive parents, implicating a potential genetic contribution to cardiovascular reactivity and possibly to CVD.

The previously mentioned studies notwithstanding, Manuck (1994) noted that previous authors have criticized the reactivity hypothesis (cf. Pickering \& Gerin, 1990) on several dimensions, including its lack of demonstrated disease relevance, the reliability of reactivity assessments (i.e., the stability of reactivity within individuals), limited generalization between laboratory assessments of cardiovascular reactivity and real-life events, and the biological plausibility of any association between acute hemodynamic reactions to stress and the pathogenesis of cardiovascular disease. Recent work by Gerin et al. (1998) lends support for 
concern regarding the generalization of cardiovascular reactivity to stress across settings, as evidenced by significantly lower lab/non-lab correlations as compared to reactivity scores compared between two laboratory stressors. Thus, the hypothesis that increased cardiovascular reactivity to stress may be one factor in the development of CVD has not achieved consensus among investigators in the field, as evidenced by the recent debate between Pickering and Schneiderman (Pickering, 1995; Schneiderman, 1995). It is entirely plausible, for example, that cardiovascular reactivity to stress may be simply a correlate or consequence of CVD, and function as a marker for CVD instead of being a causal agent.

In sum, despite a decline in the incidence and mortality of CVD in the past quarter century, it remains as the number one cause of death in the United States and other industrialized nations. Although research has identified numerous risk factors which have improved the ability to predict CVD, these account for no more than one-half of the variance in predicting its development. Cardiovascular reactivity to stress has been proposed as an additional risk factor, but its acceptance has been complicated by methodological imprecision and the lack of clearly defined biological mechanisms mediating the effects of cardiovascular reactivity on CVD. The following section will address the former of these criticisms by reviewing one methodological concern that has been identified in the assessment of cardiovascular reactivity to stress - namely the question of stability of cardiovascular reactivity to stress and its pertinence to laboratory-tolife generalization.

\section{Cardiovascular Reactivity as a Stable Individual Difference Variable}

As with measures of all other psychological/behavioral variables, if the assessment of cardiovascular reactivity to stress in the laboratory has any utility, it must exhibit acceptable indices of reliability and validity (Green, 1981). Based in psychometric theory, the validity of 
the measurement of a given construct (e.g., predictive validity) will be strongly influenced by its reliability. In light of this, it is important to demonstrate the reliability of measurement of cardiovascular reactivity to stress before making statements concerning the validity of measurement of cardiovascular reactivity to stress in predicting CVD. To these ends, it is important to demonstrate that measurement of cardiovascular reactivity to stress posseses:

a) temporal stability, b) cross-task stability, and c) cross-situation stability.

\section{Temporal Stability}

$\underline{\text { Laboratory-Based Assessment }}$

Numerous investigations have been conducted regarding the temporal stability of many psychophysiological parameters, including heart rate and blood pressure (e.g., Lovallo, Pincomb, \& Wilson, 1986; Manuck \& Garland, 1983; Manuck \& Schaefer, 1978). Methodologies of these studies have been quite similar; most measure cardiovascular reactivity to the same stressor on two different occasions interspersed by various lengths of time. The first reported investigation into the temporal stability of cardiovascular reactivity was conducted by Lacey and Lacey (1962) and involved the assessment of heart rate, systolic blood pressure, and diastolic blood pressure responses to a cold pressor task among 37 male and female children. On re-test four years later, absolute values of these responses yielded correlation coefficients ranging from .59 to .79 and change scores yielded significant reliability coefficients ranging from .44 to .75 . Recent research has confirmed these findings in both adults and children, with test-retest correlations ranging from .60 to .90 , and test-retest intervals ranging from two days to three years (Kasprowicz, Manuck, \& Krantz, 1988; Manuck \& Garland, 1980; Matthews, Rakaczky, Stoney, \& Manuck, 1987). With respect to the assessment of hemodynamic patterns of response, studies employing impedance cardiography, which permits analysis of stroke volume and cardiac output in addition 
to the standard heart rate and blood pressure determination, have shown changes induced by cognitive, psychomotor, and cold pressor tasks to be reproducible over intervals of one week, one month, and three months (Kasprowicz et al., 1988; McKinney et al., 1985; Myrtek, 1985).

Given the above results, there exists ample evidence in support of the temporal stability of cardiovascular reactivity to a given stressor as measured by HR, SBP, DBP, and hemodynamic variables (cardiac output and peripheral resistance). Based on laboratory assessments, then, these findings support the hypothesis that individuals exhibit characteristic cardiovascular responses to behavioral stressors that can be replicated at test intervals months and years later.

Ambulatory Assessment

Ambulatory monitoring refers to the process of recording participants' cardiovascular responding while they are in their natural setting. This is typically accomplished by fitting participants with lightweight, portable measuring devices that are designed to incur minimal interference or inconvenience with normal daily activities. These monitors record heart rate and blood pressure at regular intervals, and store the resulting data for statistical analysis. In a review of the temporal stability of ambulatory cardiovascular monitoring, Ward, Turner, \& Johnston (1994) concluded that there was sufficient evidence for the reproducibility of blood pressure levels across time. Only three of the seventeen reviewed studies found significant differences between SBP or DBP levels across monitoring sessions, and none found significant differences in HR. Seven studies employed correlational designs in the analysis of the reproducibility of blood pressure levels across time. For SBP, the mean reliability coefficient across these studies was .78, with a range from .54 to .97 . For DBP, the mean reliability coefficient was .73 , with a range from .36 to .93 . Only one of these studies reported results for HR across time, a correlation of .76. Though most of these studies followed a similar 
methodology, the reviewers identified several factors that may have affected the degree of reproducibility, including type of monitor used, assessment setting, number of observations employed, number of participants, BP level of participants, time between sessions, time of day, and failure to account for novelty of initial monitoring sessions.

In summary, the combined literatures of cardiovascular responsivity based on laboratory and ambulatory monitoring methods indicate that measures of cardiovascular parameters observed among individuals are quite reproducible across varying periods of time. These findings support the hypothesis that individuals' exhibit characteristic cardiovascular response magnitudes when exposed to a specific stressful situation on two or more occasions. These studies, then, have provided the necessary foundation for subsequent studies examining stability of cardiovascular reactivity across different tasks.

\section{Cross-Task Reliability}

Cross-task reliability refers to the reproducibility of cardiovascular responses to stress under varying stimulus conditions; this is typically accomplished by demonstrating that the magnitude of an individual's response to one stressor is related to the magnitude of his or her reaction to a second challenge or stressor. The stressors employed in cardiovascular reactivity research have been conceptualized as falling along numerous dimensions that have been useful for predicting expected response patterns across cardiovascular parameters. Krantz, Manuck, and Wing (1986) identified several commonly employed task dimensions that have been examined in the literature: a) "active-coping" or "passive-coping" tasks, b) "sensory intake" vs. "sensory rejection" tasks, c) tasks differing in the quality of emotional reactivity, d) tasks varying in the degree to which the participant perceives control of the stimuli (i.e., "helplessness" vs. "mastery" tasks), and e) the physical quality of the task. Since this publication, another task 
dimension, that of hemodynamic characteristic response profiles underlying the cardiovascular response to stress, has also received considerable attention (Kasprowicz, Manuck, Malkoff, \& Krantz, 1990). The following section will provide brief descriptions of these task dimensions and related patterns of cardiovascular responding.

\section{Active vs. Passive Coping}

A task is characterized as an "active-coping" task if the participant exerts instrumental control over the outcome or potential outcome of the challenge (e.g., treadmill, mental arithmetic) (Obrist, 19981). Conversely, "passive-coping" tasks are challenges in which the outcome of the performance is not directly affected by the participant's behavior (e.g., observation of a movie). Obrist (1981) demonstrated that, compared to "passive-coping" challenges, "active-coping" tasks resulted in higher SBP and HR increases, but lower increases in DBP. It has also been shown that these effects are primarily elicited by the beta-adrenergic sympathetic nervous system activity (Obrist et al., 1978). Popularly referred to as the "fight or flight response," sympathetic nervous system activitation prepares the body for vigorous muscle activity; its effects on the cardiovascular system include increased heart rate and contractile force, and increased arterial pressure resulting from vasoconstriction.

\section{Sensory-Intake vs. Sensory Rejection}

Lacey, Kagan, and Lacey (1963) are credited with making the distinction between "sensory intake" and "sensory rejection" tasks. The former is characterized by requiring that participants' attend to external stimuli (e.g., discrimination of tones or lights), while the latter requires rejecting sensory input and focusing on internal processes (e.g., mental arithmetic). Research based on such distinctions has shown deceleration in HR in response to "sensory-intake" tasks, and acceleration in HR in response to "sensory-rejection" tasks (Bunnell, 1982; Lacey et al., 1963; Lawler, 1980). 


\section{Emotional Quality}

Research investigating the relation between emotional reactions and cardiovascular responses has shown that cardiovascular responses differ across a wide range of specific emotions such as fear, anger, sadness, and disgust, as well as between positive and negative emotions generally (Ekman, Levenson, \& Friesen, 1983; Schwartz, Weinberger, \& Singer, 1981; Weinberger, Schwartz, \& Davidson, 1979). For example, in an early study, Ax (1953) found that anger was associated with larger diastolic pressure responses and smaller heart rate reactions than those measured during participants' experiences of fear.

\section{Perceived Control}

Research has shown that perceived ability to exercise control over environmental stimuli mediates the magnitude of the stress reactions resulting from exposure to aversive stimuli (Frankenhauser, 1983). However, research on this task dimension has discovered that the relation between perceived control and exerting control is complex and dependent on several factors including task difficulty (Manuck et al., 1979), the nature of the coping response utilized (e.g., active versus passive), and the physiologic response being measured (Light \& Obrist, 1980).

\section{Physical Quality}

The type of laboratory stressor employed may also vary in terms of the physical nature of the task. More specifically, characteristics such as whether dynamic or static exercise is involved (e.g., bicycle ergometer vs. hand dynamometer), as well as the type of stimulation applied (shock vs. cold pressor) clearly affect the responses elicited. For example, the cold pressor task has been shown to elicit a time-related pattern of response characterized initially by peripheral vasoconstriction that is subsequently followed by periodic vasodilation (Lovallo, 1975), and 
isometric exercise, such as that measured by use of a hand dynamometer, consistently results in increased peripheral resistance (Asmussen, 1982). In contrast, some psychologically challenging, but not physically challenging tasks (e.g., mental arithmetic), have resulted in less peripheral vasoconstriction and/or vasodilation but more cardiac activity (Williams, Bittker, Buchsbaum, \& Wynne, 1975).

Hemodynamic Patterning

Recent research has implicated differences in hemodynamic patterns as yet another significant factor in the consideration of cardiovascular reactivity to stress (Kasprowicz, Manuck, Maltoff, \& Krantz, 1990; Sherwood, Dolan, \& Light, 1990). Because blood pressure is determined jointly by the pumping actions of the heart (cardiac output) and by forces that resist blood flow (peripheral resistance), a given change in blood pressure may be the result of changes in cardiac output, peripheral resistance, or a combination of both. Thus, reliance on blood pressure measurements alone may mask important sources of variability among individuals or important information about task characteristics (Manuck, 1994). Numerous studies have demonstrated such heterogeneity of hemodynamic reactions to behaviorally-evoked pressor responses (e.g., Kasprowicz, Manuck, Malkoff, \& Krantz, 1990; Saab, et al., 1992; Sherwood, Dolan, \& Light, 1990). Further, these hemodynamic variables have displayed test-retest reliability commensurate with that for blood pressure, and research on intertask consistency has shown that the hemodynamic mechanisms responsible for pressor responses during behavioral challenge appear to be stable dispositional characteristics that are relatively impervious to situational specificity (Sherwood \& Turner, 1992).

Because different tasks evoke different cardiovascular response patterns, it has been hypothesized that cross-task reliability coefficients should be stronger for tasks that are alike on 
these dimensions in contrast to those for tasks that are different (Van Doornen \& Turner, 1992). For example, two "active-coping" tasks may be hypothesized to elicit more comparable cardiovascular reactions than contrasting an "active-coping" task with a "passive-coping" task. Data, however, has been equivocal with respect to this hypothesis. For example, among females that were assessed in response to both a cold-pressor test and mental arithmetic task, Emmons and Weidner (1988) found that SBP and HR demonstrated significant cross-task correlations (.32 and .24 respectively) while DBP did not. Further, Manuck et al. (1989) examined the consistency of HR and BP reactions across three different stressors: a psychomotor task (tracing the outline of a star guided by the design's mirror image), and two cognitive tasks (mental arithmetic and a concept formation task). Change scores yielded generalizability coefficients ranging from .57 to .82 for HR, .49 to .63 for SBP, and .49 to .57 for DBP.

Not all investigations have reported comparable correlations among participants' cardiovascular responses to different experimental tasks however. For example, McKinney et al. (1985) employed three laboratory tasks (cold pressor test and two psychomotor challenges) in their assessment of cardiovascular reactivity. Results showed that HR responses to the psychomotor tasks covaried more strongly with each other $(r=.58)$ than did HR responses to either psychomotor task with HR reactions measured during the cold pressor test $\left(\mathrm{r}^{\prime} \mathrm{s}=.22\right.$ and .32). Participants' diastolic blood pressure responses also correlated more highly between the video game and reaction time tasks $(r=.54)$ than between either of the psychomotor challenges and cold pressor test (r's $=.29$ and .35 ). Correlations for systolic blood pressure were more consistent across comparisons, ranging from .51 to .60. In contrast to Manuck et al. (1989) and van Doornen and Turner (1992), McKinney’s findings illustrate the importance of choosing similar tasks when assessing cross-task stability. 
In summary, research has shown significant correlations between different types of stressors in eliciting cardiovascular reactivity. However, findings have been inconclusive with regard to the question of whether correlations between stressors are greater when the stressors share comparable task characteristics. While the previously noted groupings of task dimensions (e.g., "sensory intake," "sensory rejection") have shown consistency in their elicited patterns of cardiovascular response, the complexity of all factors affecting consistency of response (e.g., individual differences between participants, contextual/environmental factors, subtle differences between similar but not identical tasks) preclude definitive categorizations based on cardiovascular response characteristics. As such, at this time it is more practical and defensible to organize tasks based on their structural characteristics instead of hemodynamic patterns. Based on a review of the literature, Manuck et al. (1989) concluded it is unlikely that there exists a unitary dimension of individual differences in psychophysiological reactivity that is expressed independently of the evoking stimulus characteristics with which it is associated. As such, these authors posited that the attributes of a stimulus exerted an influence on psychophysiologic response such that the "reactivity" demonstrated by individuals varies under different task conditions. These authors further note that, based on the use of single-task methodology, most previous work in this area had assumed that individual differences in cardiovascular reactivity generalized from one stimulus to another, and did not vary as a function of task influences on the overall magnitude or patterning of observed responses. In response to such assessment strategies, and as a means to better account for the heretofore inconclusive evidence supporting cardiovascular reactivity to stress as a stable construct, Manuck (1994) cited elements of psychometric theory. More specifically, he equated single-task methodology with the characteristics and predictive power of a one item test. In such an 
arrangement, there exists a greater possibility that extraneous factors will affect the attribute of interest, than an arrangement in which the participants' responses are averaged over several different tasks. The aggregation of several responses to different items, or in this case stressors, is likely to result in the "canceling out" of the extraneous factors, yielding a less contaminated index of reactivity (Manuck, 1993). Support for such a contention was provided by Kamarck (1992) with his suggestion that studies of cardiovascular reactivity to stress should incorporate three principles derived from psychometric theory. First, based on work by Thorndike (1967), he suggested that tasks be chosen based on their ability to discriminate the greatest number of respondents. Second, also based on Thorndike (1967), he suggested that extraneous sources of variance be reduced (e.g., task difficulty, practice effects). Finally, based on work by Nunnally (1967), he proposed that enhanced reliability of cardiovascular parameters would be achieved by increasing the number of tasks employed in the assessment.

Work recently cited by Manuck et al. (1993) employing a multi-task, multi-session format provided empirical support for the above suggestions, and strengthened the hypothesis that cardiovascular reactivity to stress possessed adequate stability. In a coordinated series of studies employing either three or four computerized cognitive and psychomotor tasks conducted on two separate occasions (Kamarck et al., 1992; Kamarck, Jennings, \& Manuck, 1993, Kamarck, Jennings, Stewart, \& Eddy, 1993), it was found that the combination of task standardization and aggregation over as few as three test stimuli, without multiple sessions, improved retest reliability significantly, and to a level commensurate with most psychosocial and many physical measurements routinely examined in epidemiologic research. 


\section{Laboratory to Field Generalization}

The advent and increasing availability of ambulatory cardiovascular monitoring has significantly improved the investigator's ability to observe fluctuations in cardiovascular parameters that occur in an individual's natural environment. The utility of such monitoring is evidenced by findings indicating that blood pressure measured in the patient's usual environment, away from the doctor's office, has been shown to be a better indicator of true blood pressure status (James et al., 1988), and in some studies a better predictor of cardiac consequences of hypertension than blood pressure measured in more standard settings(e.g., clinic, laboratory settings; Mancia, Casadei, Gropelli, Parati, \& Zanchetti, 1991).

In addition to the clinical merits of ambulatory monitoring, the availability of ambulatory measures of cardiovascular reactivity provides the ability to investigate the relation between field cardiovascular activity and cardiovascular reactivity measured by laboratory assessment. Because temporal stability and cross-task reliability are two important, though insufficient, conditions required to support the hypothesis that cardiovascular reactivity to stress exhibits satisfactory reliability, ambulatory assessment provides the technological tools to address the third and final component of establishing satisfactory reliability, namely laboratory-to-life generalization. In other words, if the utility of laboratory assessment is due in part to the assumption that laboratory responses reflect those occurring during natural situations, then the ability to measure actual activity and responsivity in natural situations will permit comparisons between these settings to test such an assumption.

In a recent consideration of the relation between laboratory and ambulatory cardiovascular activity based on 32 previous studies, Turner et al. (1994) concluded that the strongest relations observed are between laboratory and field levels of baseline or resting 
cardiovascular activity, with generalizability coefficients ranging from 0.6 to 0.7 . These authors also surmise, however, that the relation between laboratory measured cardiovascular reactivity and field-based cardiovascular reactivity is less consistent. In sum, several of these studies examined ambulatory cardiovascular levels in an uncontrolled fashion (i.e., during everyday activities; e.g.,. Melville and Raftery, 1980; Watson, Stallard, Flinn, \& Littler, 1980), and some were based on only one pairing of a laboratory parameter and an ambulatory parameter (e.g., Floras, Osman, Jones, \& Sleight, 1987; Turner \& Carroll, 1985), while others reported several pairings of predictor and predicted variables (e.g., Fredrickson, Blumenthal, Evans, Sherwood, \& Light, 1989). Additionally, several studies employed ambulatory variability as a measure of reactivity (e.g., Melville \& Raftery, 1980; Van Egeren \& Sparrow, 1989), while others calculated the difference between mean levels in two field categories, approximating laboratory baseline and task levels (e.g., Turner \& Carroll, 1985; Van Egeren \& Sparrow, 1989). The general findings in this area have been hotly debated, with some researchers concluding that adequate laboratory-tolife generalization has been demonstrated (Floras et al., 1987; McKinney et al., 1985; Watson et al., 1980), while others have been less impressed (Pickering, Phil, \& Gerin, 1990; Van Egeren \& Sparrow, 1989). One of the common criticisms of these studies is that comparing cardiovascular reactivity associated with laboratory challenges to ambulatory levels of cardiovascular parameters throughout daily life is somewhat of an apples-oranges comparison, as this does not provide a direct comparison between responsivity associated with challenge situations. Accordingly, only studies that have measured cardiovascular functioning in response to an actual real-life challenge could be expected to test adequately the generalization of cardiovascular reactivity from the laboratory to real life. Only six studies to date have conducted this sort of analysis. 
$\underline{\text { Studies Measuring Cardiovascular Response to Specific Field Stressors. }}$

Turner, Girdler, Sherwood, \& Light (1990) compared cardiovascular reactivity of 30 graduate, medical, or dental students to four lab tasks (two mental arithmetic tasks, two speech tasks) with a simulated speech in the natural environment. Results revealed that task levels for all four lab tasks correlated significantly with ambulatory levels for all three parameters (r's $=.35$ to .68). However, no significant correlations were noted between laboratory reactivity and ambulatory reactivity scores ( $\mathrm{r}$ 's $=-.10$ to .23 ). The inability of this study to detect relations between laboratory reactivity and field reactivity was attributed to inconsistencies in posture across settings.

In a study comparing cardiovascular reactivity among twenty-one female nurses to three laboratory stressors (mental arithmetic, cold pressor, dynamic physical exercise), Warwick-Evans, Walker, \& Evans (1988) found no significant correlations between the laboratory-based resting and reactivity cardiovascular parameters when compared to anticipation of a natural stressor (a nursing examination). One possible explanation for the lack of findings in the Warwick-Evans et al. study was that field assessment occurred 60 to 90 minutes prior to the field stressor, possibly too early to detect anticipatory changes.

Turner, Carroll, Dean, \& Harris (1987) compared cardiovascular reactivity of six high school students (three designated as "extreme high reactors", three designated as "extreme low reactors), based on their reactivity to two laboratory tasks (mental arithmetic, video game) with a public speaking task in the natural environment. Results revealed that all three participants designated as "high" laboratory reactors showed large reactivity scores during the ambulatory phase, while two of three participants designated as "low" laboratory reactors showed only modest changes. However, generalization for these findings was limited by the small sample size. 
Abel and Larkin (1991) employed twenty-two undergraduate musicians, splitting participants into high and low laboratory reactors based on anticipation of mental arithmetic and a visual-verbal concepts challenge. In comparing these laboratory responses to ambulatory reactivity (anticipation of an evaluated musical performance), their results indicated generalization of response to the natural setting for SBP, but not HR or DBP. Although the anticipation responses exhibited significant relations across situations, measures during the laboratory stressors were unrelated to anticipation of the musical jury performance in the natural environment.

Van Doornen and van Blokland (1992) compared cardiovascular reactivity of 33 male doctoral candidates to three laboratory tasks (reaction time, tracking task, and cold pressor test) with ambulatory measures taken prior to their thesis defense (comprising an anticipation period) and ambulatory levels taken during a control day (in order to yield ambulatory reactivity scores). Results revealed complex laboratory-to-life relations. For example, laboratory HR reactivity to the reaction time task correlated significantly with ambulatory SBP level $(\mathrm{r}=.52)$ and ambulatory SBP reactivity $(\mathrm{r}=.58)$, but with neither HR values. For the cold pressor test, laboratory HR reactivity correlated significantly with ambulatory reactivity and ambulatory levels for both SBP and DBP, but not for HR. These authors further found that the HR responses to the reaction time task and the HR and DBP reaction to the cold pressor test significantly improved prediction of ambulatory BP levels and responses beyond the prediction based on baseline values.

Finally, Matthews, Manuck, \& Saab (1986) divided 25 tenth grade participants into "reactors" and "non-reactors" based on responsivity to three laboratory tasks (serial subtraction, star-tracing, and hand grip tasks) for each cardiovascular parameter (HR, DBP, SBP) for each task. These groups were then compared on field measures obtained prior to, and following a speech task given in an English class. Results revealed that SBP and DBP reactors to the serial 
subtraction task showed larger elevations in SBP and DBP in the naturalistic setting. DBP reactors to the star-tracing task showed higher DBP in the naturalistic setting, and HR reactors to the handgrip task showed higher HR in the naturalistic setting.

Studies examining the generalizability of laboratory-based findings to field, or "real life," responses have yielded mixed results, with some providing support for generalization (e.g., Abel \& Larkin, 1991; Matthews et al., 1986; Turner et al., 1987) and others failing to support generalization (e.g., Turner et al., 1990; Warwick-Evans et al, 1988). Turner et al. (1994) suggested that positive findings were likely due to the correspondence between the psychological meaning of the laboratory and field tasks. While this correspondence has been hypothesized to increase the reliability between laboratory stressors and life events, these, and several other authors (Pickering \& Gerin, 1990; van Doornen \& Turner, 1992; Van Egren \& Gellman, 1992) caution against an over-reliance on explaining such phenomena through task similarities. Further, demonstrated associations between similar pairings of laboratory-field stressors would limit generalizations from the laboratory to only those real-life tasks that were similar in nature to those employed in the laboratory assessment. Stated differently, if cardiovascular reactivity is to be considered a stable individual difference, it is most likely to have its effect on the development of CVD by virtue of increased reactivity to various and numerous classes of stimuli. After all, most of daily life involves various stimuli rather than repetitive presentations of stressful stimuli.

\section{Statement of the Problem}

If the construct of cardiovascular reactivity is to be useful in the identification of risk factors related to the development of CVD, it must first be shown to possess adequate indices of reliability, supporting its designation as a stable individual difference variable. Three specific attributes of individual differences have been posited as possessing significance in this regard: 1) 
temporal stability, 2) cross-task stability, and 3) the generalization of individual differences from laboratory evaluations to measurements obtained in natural settings (Manuck et al., 1989). Previous work has demonstrated support for the temporal and cross-task stability in the assessment of cardiovascular reactivity to stress. However, the evidence has been less compelling with regard to generalization of findings between laboratory and field measurements of cardiovascular function. Although evidence of laboratory-to-field generalization have been more consistent for absolute cardiovascular levels than measures of laboratory reactivity, consensus has yet to emerge regarding laboratory-to-life generalizability of this potentially important variable.

In response to criticisms (c.f., Parati et al., 1991) concerning the validity of cardiovascular reactivity to stress as a dispositional attribute, Manuck (1994) suggested that the reconciliation of a desire to demonstrate dispositional reactivity with only modest evidence of the reproducibility of this characteristic may lie in the scarcity of observation that typically comprises the reactivity assessment. More specifically, much of the previous research investigating reactivity has relied on participants' responses to a single stimulus on a single occasion. With such designs there is a greater likelihood that responses to any single item are likely to be influenced by factors other than the attribute of interest (e.g., fatigue, distraction, familiarity with a particular stimulus) in comparison to protocols measuring cardiovascular reactivity to multiple test stimuli across different time sequences. This latter strategy, which allows for the averaging of participants' responses, hypothetically results in a much more stable estimate of cardiovascular reactivity to stress than those employing single stressors.

Manuck et al. (1993) employed a multi-task, multi-session format that provided empirical support for considering cardiovascular reactivity to stress a dispositional attribute. In a coordinated series of studies employing either three or four computerized cognitive and 
psychomotor tasks conducted on two separate occasions, it was found that the combination of task standardization and aggregation over as few as three test stimuli, without multiple sessions, improved retest reliability significantly, and to a level commensurate with most psychosocial and many physical measurements routinely examined in epidemiologic research. This multi-task methodology, however, has yet to be examined in relation to reliability of lab-to-life generalization involving the assessment of cardiovascular functioning during a naturally occuring stressor.

Because the utility of multi-task methods for improving reliability of cardiovascular reactivity measures in the laboratory has been documented (Manuck et al., 1993; Kamarck, 1992), the purpose of the present study is to examine the utility of such a method for improving reliability estimates in a study of lab-to-life generalization. For the purposes of the present study, cardiovascular reactivity to stress was measured in a homogenous student population (graduate students) in two settings: a) during five standard stressors presented in a laboratory setting, and b) during a naturally occurring, relatively standardized stressor (proposal or defense of a thesis or dissertation). This stressor was chosen because it provides a relatively standard stressor encountered in the lives of graduate students, a high likelihood that it will elicit significant physiologic arousal, and because it is a naturally occurring event for this population. In addition to the assessments of cardiovascular reactivity to the proposal/defense event, a laboratory-based assessment of cardiovascular reactivity was conducted using a series of different types of standard laboratory stressors. The laboratory stressors included: a) a 3 minute oral presentation), b) mental arithmetic, c) a mirror tracing challenge, d) a hand-grip challenge, and e) viewing three minutes of a stressful movie scene. These five laboratory challenges were chosen because they provided a variety of demands with different task dimensions and patterns of cardiovascular responding on a number of the task parameters previously explained (e.g., "active- 
coping" vs. "passive coping"; physical vs. psychological).

A secondary issue to be investigated concerns the consistency of individual responding to multiple stimuli, and whether individuals with greater consistency of responding to the laboratory stressors (i.e., high response stereotypic individuals) show significantly different patterns of responding during the naturally occurring challenge compared to individuals with lower levels of consistency in the laboratory environment (i.e., low response stereotypic individuals). Individual consistency, or response stereotypy has been defined as the tendency to emit "a consistent hierarchy of responses to a set of stimuli” (Engel, 1972; Fahrenberg, Walschenburger, Foerster, Myrtek, \& Muller, 1979), and suggests that responses are a function of individuals rather than stimuli. Early work in this area demonstrated greater stereotypy in hypertensive females as compared to normotensive females (Engel and Bickford, 1961), as well as consistent differences in responding between arthritic and hypertensive patients (Moos \& Engel, 1962). In 1982, additional support for the utility of this concept was provided by Garwood, Engel, and Capriotti, who found that individual response stereotypy increased with increasing age. For the purposes of this study, patterns of responding were compared between groups demonstrating high and low levels of response stereotypy. 


\section{Hypotheses}

1) It was hypothesized that there would be no differences between resting levels of cardiovascular activity during each rest period in the laboratory assessment.

2) Given its importance to the participants, it was further hypothesized that the degree of observed cardiovascular reactivity would be greatest in response to the naturally occurring stressor in comparison to all laboratory stressors.

3) Based on its similarity to the naturally occurring stressor, it was hypothesized that the cardiovascular reactivity associated with the laboratory speech challenge would demonstrate the greatest correlation with the naturally occurring stressor, as compared with all other laboratory stressors.

4) Based on previous work by Manuck et al. (1993), it was hypothesized that the use of an aggregate score based on cardiovascular reactivity to the five laboratory stressors would significantly improve the reliability coefficient between laboratory and ambulatory measures of cardiovascular reactivity as compared to the use of any single laboratory challenge. 


\section{Method}

\section{Sample Characteristics and Design}

\section{$\underline{\text { Participants }}$}

Twenty seven West Virginia University psychology graduate students were recruited through campus mailings for voluntary participation in this study, and each was paid ten dollars remuneration for his or her involvement. Although all participants completed this protocol, data from five subjects were not included due to technical errors during data collection, thus resulting in a total sample of twenty two. The total number of persons solicited through the mailings was 80 , resulting in a response rate of approximately $34 \%$. No participants were excluded due to medical factors or medication (e.g., over the counter or prescription) or stimulant (e.g., coffee, tobacco) use, and none had participated in vigorous exercise during the hour prior to either assessment. Cardiovascular measures were obtained from participants during two assessment periods; one conducted in a laboratory setting, and the other conducted in a setting outside of the laboratory (the proposal or defense of a thesis or dissertation).

Although it was intended that all subjects would complete these assessments in the same order (laboratory first), four participants completed the naturally occurring assessment first due to scheduling difficulties. Measures of cardiovascular function of these four subjects differed from the remaining eighteen participants only on resting heart rate $(\mathrm{p}<.05)$. The four participants who completed the assessment during their proposal/defense meeting first exhibited greater heart rate during rest periods preceding the mirror trace, movie scene, and math challenges than the larger group. Because there were no differences between these two groups in terms of absolute values of cardiovascular parameters during each challenge [Systolic Blood Pressure, $\mathrm{F}(1,19)=.02$, Diastolic Blood Pressure, F(1,19)=.09, and Heart Rate, F (1,19)=2.16] or change 
scores in response to each challenge [Systolic Blood Pressure, $F(1,19)=2.61$, Diastolic Blood Pressure, $\mathrm{F}(1,19)=.34$, and Heart Rate, $\mathrm{F}(1,19)=.64]$ and there were no Group by Period interactions, the data from these two groups were combined for the remainder of the analyses.

The final sample consisted of sixteen women and six men, with an average age of $28 \pm 5.5$ years. Eleven participants reported a family history of hypertension, and two regularly used tobacco products. Participants reported exercising an average of $191.9 \pm 144$ minutes per week, and as a group they were not overweight. The average height and weight for the men were 5'10" $\pm 2.9^{\prime \prime}$ and $168 \# \pm 15 \#$, respectively, and for the women were $5^{\prime} 5^{\prime \prime} \pm 3.1^{\prime \prime}$ and $132 \# \pm 18 \#$, respectively.

Individual response stereotypy was investigated by calculating intraclass correlations using cardiovascular response data to all 5 laboratory challenges. For this analysis, subjects were divided into two groups designated as either stereotypic (consistent) or non-stereotypic (inconsistent) responders based on a median split of the intraclass correlations derived from their residualized change scores to all five laboratory challenges. Within the stereotypic group there were five SBP responders, four HR responders, and one mixed SBP/DBP responder. Experimental Challenges

Proposal or Defense of a Thesis or Dissertation. The naturally occurring stressor consisted of the participant's proposal or defense of his or her thesis or dissertation to an examining committee. The committee's decision regarding the acceptability of the proposal or defense is a significant factor in determining whether a student is allowed to continue towards the completion of his or her academic degree, thus constituting a significant naturally occurring stressor for the student. Assessment of cardiovascular parameters occurred prior to this event (yielding anticipatory levels) and during the event (yielding task levels). 
Mirror tracing task. Each participant was instructed to trace the outline of a six-point star using only the design's mirror image. Participants were instructed to trace the star as quickly and as accurately as possible. A direct view of the image was shielded so that the participants relied solely on the mirror image. The mirror tracing task has been used as a standard stressor in numerous studies and has been shown to evoke substantial pressor responses ( Matthews et al., 1987).

Mental arithmetic challenge. The mental arithmetic task involved subtraction by seventeens from a four-digit number provided by the experimenter. A different number was presented each minute during the three-minute challenge. Each participant was instructed to subtract continuously by seventeens in his or her head and state the answer aloud into a microphone until instructed to stop. The mental arithmetic challenge, like the mirror tracing challenge, has been used often in laboratory investigations, and has been shown to evoke both substantial heart rate and blood pressure responses (Manuck \& Garland, 1980; Matthews et al., 1987).

Hand grip challenge. Using the dominant hand, each participant was asked to exert a maximal voluntary contraction using a hand dynamometer, and then sustain a force of 30 percent of maximum voluntary contraction for three minutes. As with both the mirror tracing and mental arithmetic challenges, the hand grip challenge has been used extensively in laboratory investigations of cardiovascular responding, and has been shown to elicit significant heart rate and blood pressure responses (Faultisch, et al., 1986).

Movie scene. Each participant watched three minutes of a frightening movie scene from a popular film, Cliffhanger. This specific scene was chosen due to its dramatic intensity and because of the probability that it would elicit an emotional response (fear) similar to that expected in response to the natural stressor. In contrast to the three previous stressors, however, 
it has not been used in previous investigations. Video stimuli of other sorts, though, have been used previously and shown to elicit substantial cardiovascular responses (McKinney et al., 1985).

Speech challenge. Each participant was required to present an unrehearsed, spontaneous three minute oral presentation of his or her view of a controversial social issue (capital punishment). Although challenges requiring the presentation of a prepared speech have been employed in past research (Matthews et al., 1986; Turner et al., 1990; Turner et al., 1987;), and have been shown to elicit significant pressor and heart rate responses, this particular format has not been used previously in this literature.

\section{$\underline{\text { Cardiovascular Assessment }}$}

Heart rate (HR) and blood pressure (BP) were assessed in both settings with an ambulatory blood pressure monitor (Colin ABPM-630). Blood pressure was measured using an occluding cuff positioned over the brachial artery of the participant's non-dominant arm, and was determined via the Korotkoff-Riva Rocci method. Heart rate was calculated from cuff pulsations as an integrated six second average. The Colin ABPM-630 was chosen because it is lightweight (1.8 pounds) and could be worn without disturbing the participant or others during either assessment session. After both assessments were completed, the data were down-loaded via memory cassette and analyzed with a PC-630 computer processing unit interfaced with an IBM compatible computer.

\section{$\underline{\text { Procedure }}$}

\section{$\underline{\text { Laboratory Session }}$}

Each participant first read and signed a consent form, after which the recording apparatus described above was attached. He or she was then asked to sit quietly for a ten minute adaptation period. Following adaptation, $\mathrm{HR}$ and $\mathrm{BP}$ were taken three times while the participant sat quietly for a six-minute rest period. HR, SBP, and DBP were determined at the beginning of this period, 
and at two minute intervals thereafter. Following the initial rest period, the participant began involvement in the first of five laboratory stressors. The laboratory stressors were presented in one of twenty unique sequences arranged such that no two challenges followed each other systematically in order to prevent potential confounding of variables due to order effects. Prior to the challenge, participants were provided with instructions on: how to perform the challenge, instructions to disregard the inflation and deflation of the occlusion cuff, and finally a warning that "the task will begin in about four minutes." Following this warning, HR and BP measurements were taken twice during a four-minute anticipation period. Each participant then completed the three-minute laboratory challenge during which time BP and HR were again taken twice. This challenge was followed by a second six-minute rest period, four-minute adaptation period, and three-minute task period, identical to the first sequence described above. This sequence continued until the participant completed all five challenges. Following completion of the final challenge, participants underwent one final six minute rest period identical to those described above. This procedure yielded cardiovascular data during six rest periods, five anticipation periods, and five task periods. The apparatus was removed and a meeting time was scheduled for the natural assessment.

\section{$\underline{\text { Ambulatory Assessment }}$}

The ambulatory assessment occurred in a conference room in Oglebay Hall on the campus of West Virginia University, as determined by the participant and his/her committee members. No attempt was made to standardize the ambulatory setting. The mean duration in days between laboratory and natural setting assessments was $4.4 \pm 4.7$. Participants were asked to arrive at a designated room in the building forty-five minutes prior to the scheduled meeting. 
After attaching the ambulatory apparatus, each participant was instructed to sit quietly during a ten minute adaption period, after which he/she was asked to disregard the monitoring equipment, and $\mathrm{BP}$ and $\mathrm{HR}$ were measured during a four minute anticipation period in a manner identical to the laboratory assessment. Participants were then free to prepare for the upcoming meeting. Upon beginning the proposal or defense, participants activated the ambulatory blood pressure monitor, and during the first four minutes of the proposal/defense, HR and BP were taken twice.

\section{$\underline{\text { Data Reduction }}$}

HR and BP measurements were obtained three times during each rest period, two times during each anticipation period, and two times during each laboratory stressor and the defense/proposal meeting. For purposes of data analysis, the cardiovascular values obtained within each period (resting, anticipation, task) were averaged to obtain a mean value for each period. Residualized change scores were created by regressing the cardiovascular levels obtained during the rest periods preceding each of the five laboratory challenges on the ensuing task scores. Residualized change scores for the proposal/defense meeting were determined by regressing the cardiovascular levels obtained during the final laboratory rest period on the values obtained during the proposal/defense. ${ }^{1}$

\section{RESULTS}

\section{Cardiovascular Parameters During Rest, Anticipation and Task Periods}

A 3 X 6 [Period (resting, anticipation, task) X Task (handgrip, mental arithmetic, mirror trace, movie scene, speech, proposal/defense)] repeated measures ANOVA was conducted on absolute values of SBP, DBP, and HR to investigate the degree of cardiovascular responding

\footnotetext{
${ }^{1}$ Simple change scores were also calculated using preceding rest periods and the final rest period; in all cases, simple change score analyses were comparable to those using residualized change scores. Residualized change scores allow for the statistical "removal" of baseline differences among individuals, resulting in a "purer" measure of reactivity.
} 
during both anticipation and task assessment periods for all six challenges. Each of these analyses demonstrated significant main effects for both Period and Task as well as significant Period X Task interactions which confirm that cardiovascular changes were observed for each challenge.

Systolic Blood Pressure. The repeated measures ANOVA on SBP revealed significant main effects for Period, $\mathrm{F}(2,36)=180.2, \mathrm{p}<.001$, and Task, $\mathrm{F}(5,90)=26.12, \mathrm{p}<.001$, and the Period X Task interaction was also significant, $\mathrm{F}(10,180)=14.2, \mathrm{p}<.001$. Follow-up analyses on the Period X Task interaction revealed that all anticipation and rest periods resulted in significantly lower SBP's than during performance of each challenge (p's $<.03$ ). Inspection of the rest versus anticipation periods indicated that although no significant differences in SBP were observed for the handgrip, math, mirror trace, and movie challenges, SBP during anticipation periods for both the speech and proposal/defense was significantly greater than rest periods, (p's <.001).

Examination of SBP during the rest periods indicated no significant differences across the six rest periods. However, significant differences in SBP responding did emerge during the anticipation and task periods. More specifically, during the anticipation period, although there were no SBP differences between anticipation of the handgrip, math, mirror trace, and movie scene challenges, all showed lower levels of SBP than anticipation of both the speech and proposal/defense. SBP during anticipation of the speech challenge was greater than during anticipation of all other laboratory challenges (p's $<.001)$, and less than that observed during anticipation of the proposal/defense $(\mathrm{p}<.05)$. SBP in anticipation of the proposal/defense was greater than that occurring during all other anticipation periods (p's < 05). During the task period, SBP during the movie scene challenge was significantly lower than all other challenges $(\mathrm{p}<.02)$. There were no significant differences in SBP during the handgrip, math, and mirror 
trace challenges, all of which were significantly lower than the proposal/defense $(\mathrm{p}<.001)$, and SBP during the speech challenge was significantly greater than all other laboratory challenges except for the handgrip challenge $(\mathrm{p}=.07)$, but was significantly lower than SBP during the proposal/defense $(\mathrm{p}<.001)$. SBP during the proposal/defense was significantly higher than SBP during all laboratory challenges $(\mathrm{p}<.001$; See Table 1$)$.

Table 1

Systolic Blood Pressure:

Rest, Anticipation, and Task Period

Means and (Standard Deviations)

\begin{tabular}{ccccccc}
\hline Period & Handgrip & Math & Mirror Trace & Movie & Speech & Natural \\
\hline \multirow{2}{*}{ Rest } & $117.36^{\mathrm{a}}$ & $116.98^{\mathrm{a}}$ & $118.71^{\mathrm{a}}$ & $117.31^{\mathrm{a}}$ & $116.33^{\mathrm{a}}$ & $118.12^{\mathrm{ab}}$ \\
& $(9.58)$ & $(8.72)$ & $(7.77)$ & $(7.97)$ & $(9.92)$ & $(9.16)$ \\
\multirow{2}{*}{ Anticipation } & $116.98^{\mathrm{a}}$ & $118.64^{\mathrm{ab}}$ & $118.57^{\mathrm{ab}}$ & $116.89^{\mathrm{a}}$ & $123.89^{\mathrm{c}}$ & $128.48^{\mathrm{d}}$ \\
& $(10.69)$ & $(9.88)$ & $(9.89)$ & $(8.31)$ & $(9.46)$ & $(8.63)$ \\
\multirow{2}{*}{ Task } & $126.17^{\mathrm{ce}}$ & $125.09^{\mathrm{c}}$ & $124.91^{\mathrm{c}}$ & $120.84^{\mathrm{b}}$ & $132.43^{\mathrm{e}}$ & $148.50^{\mathrm{f}}$ \\
& $(13.93)$ & $(10.15)$ & $(10.13)$ & $(10.52)$ & $(12.08)$ & $(15.35)$ \\
\hline
\end{tabular}

Means that share a common superscript are not significantly different

Diastolic Blood Pressure. The ANOVA on DBP resulted in significant main effects for both Period, $\mathrm{F}(2,36)=108.7, \mathrm{p}<.001$, and Task, $\mathrm{F}(5,90)=22.8, \mathrm{p}<.001)$. The Period $\mathrm{X}$ Task interaction, $\mathrm{F}(10,180)=8.9, \mathrm{p}<.001$, was also significant. Follow-up analyses were similar to those obtained for SBP; significant differences were observed between anticipation and task DBP levels (p's $<.001)$ as well as between rest and task DBP levels for all challenges $(\mathrm{p}<.02)$.

As with SBP, there were no differences in resting DBP among challenges during the rest period. However, significant differences were observed between challenges across the anticipation and task periods. For the anticipation period, the handgrip, math, and movie scene challenges demonstrated the lowest levels of DBP and were not significantly different. DBP during anticipation of the mirror trace challenge was greater than DBP during anticipation of the movie 
scene challenge, but was not significantly different than DBP during anticipation of the math and handgrip challenges. DBP during anticipation of the speech challenge was significantly greater than anticipation of all of the other laboratory challenges but significantly less than the proposal/defense $(\mathrm{p}<.02)$, and DBP during anticipation of the proposal/defense was greater than all other challenges $(\mathrm{p}<.02)$. For DBP during the task period, the movie challenge was significantly lower than all other challenges, and there were no significant differences in DBP during the math, handgrip, and mirror trace challenges. With the exception of the handgrip challenge, DBP during the speech challenge was significantly greater than all other laboratory challenges $(\mathrm{p}<.02)$, and DBP during the proposal/defense was greater than during all other challenges $(\mathrm{p}<.001$; see Table 2$)$.

Table 2

Diastolic Blood Pressure:

Rest, Anticipation, and Task Period

Means and (Standard Deviations)

\begin{tabular}{ccccccc}
\hline Period & Handgrip & Math & Mirror Trace & Movie & Speech & Natural \\
\hline \multirow{2}{*}{ Rest } & $70.58^{\mathrm{ab}}$ & $71.30^{\mathrm{ab}}$ & $69.66^{\mathrm{ab}}$ & $70.35^{\mathrm{ab}}$ & $69.30^{\mathrm{a}}$ & $71.73^{\mathrm{a}}$ \\
& $(6.04)$ & $(7.92)$ & $(5.86)$ & $(5.61)$ & $(5.69)$ & $(8.37)$ \\
\multirow{3}{*}{ Anticipation } & $69.70^{\mathrm{ab}}$ & $70.30^{\mathrm{ab}}$ & $70.93^{\mathrm{bc}}$ & $69.61^{\mathrm{a}}$ & $74.45^{\mathrm{de}}$ & $78.25^{\mathrm{f}}$ \\
& $(5.92)$ & $(6.21)$ & $(5.65)$ & $(5.28)$ & $(6.03)$ & $(5.69)$ \\
\multirow{2}{*}{ Task } & $78.50^{\mathrm{fg}}$ & $75.73^{\mathrm{ef}}$ & $76.25^{\mathrm{ef}}$ & $72.66^{\mathrm{cd}}$ & $79.95^{\mathrm{g}}$ & $89.36^{\mathrm{h}}$ \\
& $(9.29)$ & $(6.73)$ & $(7.01)$ & $(7.31)$ & $(7.48)$ & $(10.50)$ \\
\hline
\end{tabular}

Means that share a common superscript are not significantly different.

Heart Rate. The ANOVA on HR also showed significant main effects for Period, $\mathrm{F}(2,36)=157.1, \mathrm{p}<.001$, and Task, $\mathrm{F}(5,90)=54.1, \mathrm{p}<.001$, and a significant Period $\mathrm{X}$ Task interaction, $\mathrm{F}(10,180)=29.18, \mathrm{p}<.001$. Follow-up analyses on the Period $\mathrm{X}$ Task interaction were slightly different for HR as compared to the blood pressure measures. In comparing HR during rest versus HR during anticipation, significant differences were noted for the handgrip, 
math, speech, and proposal/defense (p's < .005). Similar to the blood pressure findings, significant differences existed for all of the challenges when comparing HR during anticipation versus HR during the challenge. In addition, significant differences existed between all HR's during rest versus HR during challenge performance, except for the movie challenge which only approached significance $(\mathrm{p}=.08)$.

Significant differences were observed between the challenge rest periods, as well as during the anticipation and task periods. During the rest period, HR was significantly greater prior to the handgrip as compared to HR prior to the math challenge $(\mathrm{p}<.01)$, speech challenge $(\mathrm{p}<.05)$, or the final rest period $(\mathrm{p}=.02)$. In addition, resting HR prior to the math challenge was less than the resting HR prior to the mirror tracing challenge $(\mathrm{p}=.03)$ and the movie scene $(\mathrm{p}<.05)$. During the anticipation period, HR levels during the movie scene challenge were significantly lower than HR during anticipation of the handgrip and speech challenges $(\mathrm{p}<.005)$, but were not significantly different from HR during anticipation of the math and mirror trace challenges. HR levels in anticipation of the math challenge were less than those during anticipation of the handgrip, speech, and proposal/defense $(\mathrm{p}<.01)$, while HR levels in anticipation of the mirror trace challenge were significantly less than those during anticipation of the speech and the proposal/defense $(p<.01)$ but were not significantly different from those in anticipation of the handgrip challenge. HR during anticipation of the handgrip challenge was greater than HR during anticipation of the math and movie challenges $(\mathrm{p}<.01)$, but not the mirror trace or speech challenges, and was significantly less than anticipation of the proposal/defense $(\mathrm{p}<.001)$. Finally, responding during anticipation of the speech challenge was significantly greater than all other laboratory challenges, but was significantly less than during anticipation of the proposal/defense $(\mathrm{p}<.001)$, and responding in anticipation of the proposal/defense was was greater than all other challenges $(\mathrm{p}<.001)$. 
Regarding HR during challenge performance, HR during the movie scene challenge was significantly lower than during all other challenges $(\mathrm{p}<.05)$. There were no significant differences in HR during the handgrip, math, and mirror trace challenges, but HR during the speech challenge was significantly greater than all other laboratory challenges $(\mathrm{p}<.005)$, but was significantly less than the proposal/defense $(\mathrm{p}<.001)$. HR during the proposal/defense was significantly greater than all other challenges $(\mathrm{p}<.001$; see Table 3$)$.

Table 3

Heart Rate:

Rest, Anticipation, and Task Period

Means and (Standard Deviations)

\begin{tabular}{|c|c|c|c|c|c|c|}
\hline Period & Handgrip & Math & Mirror Trace & Movie & Speech & Natural \\
\hline Rest & $\begin{array}{c}69.46^{\mathrm{b}} \\
(11.11)\end{array}$ & $\begin{array}{c}66.70^{\mathrm{a}} \\
(11.76)\end{array}$ & $\begin{array}{l}68.43^{\mathrm{bc}} \\
(10.67)\end{array}$ & $\begin{array}{l}69.17^{\mathrm{bc}} \\
(11.34)\end{array}$ & $\begin{array}{c}68.24^{\mathrm{ac}} \\
(10.11)\end{array}$ & $\begin{array}{l}67.76^{\mathrm{ac}} \\
(10.81)\end{array}$ \\
\hline Anticipation & $\begin{array}{l}71.73^{\text {de }} \\
(11.69)\end{array}$ & $\begin{array}{l}69.43^{\mathrm{bc}} \\
(11.07)\end{array}$ & $\begin{array}{l}69.77^{\mathrm{bc}} \\
(12.20)\end{array}$ & $\begin{array}{l}68.16^{\mathrm{ab}} \\
(11.13)\end{array}$ & $\begin{array}{c}74.77^{\mathrm{ef}} \\
(13.01)\end{array}$ & $\begin{array}{c}91.00^{\mathrm{h}} \\
(13.88)\end{array}$ \\
\hline Task & $\begin{array}{c}76.71^{\mathrm{f}} \\
(11.52)\end{array}$ & $\begin{array}{c}76.66^{\mathrm{f}} \\
(12.97)\end{array}$ & $\begin{array}{c}75.95^{\mathrm{f}} \\
(12.84)\end{array}$ & $\begin{array}{l}71.82^{\text {cde }} \\
(13.17)\end{array}$ & $\begin{array}{c}84.70^{\mathrm{g}} \\
(14.01)\end{array}$ & $\begin{array}{l}112.57^{\mathrm{i}} \\
(21.76)\end{array}$ \\
\hline
\end{tabular}

Means that share a common superscript are not significantly different.

\section{Comparison of Challenge Reactivity Scores}

Tables 4-6 present the means and standard deviations of the change scores for each of the six challenges. Change scores for each of the five laboratory challenges were determined by subtracting the averaged rest period values preceding each challenge from the ensuing values taken during the laboratory challenge. The reactivity score for the proposal/defense was obtained by subtracting the averaged final rest period value obtained in the laboratory assessment from the value obtained during the proposal/defense. A repeated measures ANOVA was conducted on change scores for all three cardiovascular parameters. Significant task differences were observed 
for Systolic Blood Pressure, F(5,100) = 21.30, $\mathrm{p}<.0001$; Diastolic Blood Pressure, $\mathrm{F}(5,100)=$ 14.44, $\mathrm{p}<.0001 ;$ and Heart Rate, $\mathrm{F}(5,100)=49.87, \mathrm{p}<.0001$.

Systolic Blood Pressure Change. Results show that SBP change measured in the natural setting was significantly greater than the SBP reactivity associated with any laboratory challenges (p's <.01), and that SBP reactivity associated with the speech challenge was significantly greater than that associated with the movie challenge $(\mathrm{p}<.01)$ and the mirror trace challenge $(\mathrm{p}<.05)$, but not the math and handgrip challenges. There were no significant differences in SBP reactivity among the handgrip, math, mirror trace, and movie scene challenges. (See Table 4)

Table 4

Systolic Blood Pressure:

Change Score Means and (Standard Deviations)

\begin{tabular}{cccccc}
\hline Handgrip & Math & Mirror Trace & Movie & Speech & Natural \\
\hline $9.40^{\mathrm{bc}}$ & $8.11^{\mathrm{bc}}$ & $6.20^{\mathrm{c}}$ & $3.71^{\mathrm{c}}$ & $16.11^{\mathrm{b}}$ & $30.38^{\mathrm{a}}$ \\
$(8.56)$ & $(6.37)$ & $(5.25)$ & $(7.27)$ & $(8.88)$ & $(15.80)$ \\
\hline
\end{tabular}

Means with different superscripts are significantly different $(\mathrm{p}<.05)$

Diastolic Blood Pressure Change. Results were very similar to those obtained for the SBP data. DBP change associated with the proposal/defense was significantly greater than all other challenges (p's $<.01$ ), and the reactivity associated with the speech challenge was greater than that associated with the movie and math challenges, but was not significantly different from the DBP reactivity associated with the mirror trace and handgrip challenges. The DBP reactivity associated with the handgrip challenge was significantly greater than that associated with the movie scene challenge $(\mathrm{p}<.05)$, but was not significantly different from the DBP reactivity associated with the math and mirror trace challenges. Finally, there were no significant differences in DBP reactivity among the movie scene, mirror trace, and math challenges. 
Table 5

Diastolic Blood Pressure:

Change Score Means and (Standard Deviations)

\begin{tabular}{cccccc}
\hline Handgrip & Math & Mirror Trace & Movie & Speech & Natural \\
\hline $8.41^{\mathrm{bc}}$ & $4.42^{\mathrm{cd}}$ & $6.59^{\mathrm{bcd}}$ & $2.31^{\mathrm{d}}$ & $10.66^{\mathrm{b}}$ & $18.52^{\mathrm{a}}$ \\
$(6.80)$ & $(8.07)$ & $(4.52)$ & $(4.58)$ & $(5.99)$ & $(9.82)$ \\
\hline
\end{tabular}

Means with different superscripts are significantly different $(\mathrm{p}<.05)$

Heart Rate Change. Finally, the general pattern of differences for the heart rate change scores was similar to that demonstrated by both blood pressure parameters. HR change associated with the proposal/defense was significantly greater than all other challenges (p's $<.01)$, and HR change during the speech challenge was significantly greater than that associated with the movie scene $(\mathrm{p}<.01)$, as well as the mirror trace and handgrip challenges ( $\mathrm{p}$ 's $<.05)$, but not the math challenge. Finally, there were no significant differences in HR reactivity among the math, handgrip, mirror trace, and movie scene challenges. (See Table 6).

Table 6

Heart Rate:

Change Score Means and (Standard Deviations)

\begin{tabular}{cccccc}
\hline Handgrip & Math & Mirror Trace & Movie & Speech & Natural \\
\hline $7.54^{\mathrm{c}}$ & $9.96^{\mathrm{bc}}$ & $7.52^{\mathrm{c}}$ & $2.65^{\mathrm{c}}$ & $16.47^{\mathrm{b}}$ & $44.80^{\mathrm{a}}$ \\
$(5.08)$ & $(3.80)$ & $(5.64)$ & $(6.89)$ & $(8.31)$ & $(20.20)$ \\
\hline
\end{tabular}

Means with different superscripts are significantly different $(\mathrm{p}<.05)$

\section{Correlation Among Anticipation Periods and Task Periods}

Correlational analyses using Pearson product moment correlation coefficients were conducted on absolute cardiovascular parameter levels measured during anticipation (See Tables 7-9), and challenge performance periods (See Tables 10-12). Residualized change scores for anticipation period responses (See Tables 13-15) and challenge performance responses (See Tables 16-18) for each cardiovascular parameter were also examined through correlational analyses. Due to technical errors, data was not obtained during the handgrip challenge for one participant, and during the anticipation 
period prior to the natural assessment for two participants. Therefore, $r$ values for all anticipation analyses are based on 20 participants, and r values for the handgrip are based on 21 subjects.

$\underline{\text { Anticipation Values }}$

Correlations among laboratory challenges. Correlational analyses among anticipation of each of the 5 laboratory challenges revealed significant correlations for each of the cardiovascular parameters (p's <.001); for SBP, r's ranged from .71 to .92; for DBP, r's ranged from .79 to .88; and for HR, r's ranged from .78 to .94. (See Tables 7-9).

Table 7

Absolute Values of Systolic Blood Pressure During Challenge Anticipation Bivariate Correlations (and $\mathrm{P}$ values) (Two-tailed Significance)

\begin{tabular}{|c|c|c|c|c|c|c|}
\hline & Handgrip & Math & Mirror Trace & Movie & Speech & Natural \\
\hline Handgrip & 1.00 & $\begin{array}{c}.77 \\
(.001)\end{array}$ & $\begin{array}{c}.85 \\
(.001)\end{array}$ & $\begin{array}{c}.71 \\
(.001)\end{array}$ & $\begin{array}{c}.85 \\
(.001)\end{array}$ & $\begin{array}{c}.40 \\
(.08)\end{array}$ \\
\hline Math & & 1.00 & $\begin{array}{c}.92 \\
(.001)\end{array}$ & $\begin{array}{c}.78 \\
(.001)\end{array}$ & $\begin{array}{c}.88 \\
(.001)\end{array}$ & $\begin{array}{c}.48 \\
(.03)\end{array}$ \\
\hline Mirror Trace & & & 1.00 & $\begin{array}{c}.83 \\
(.001)\end{array}$ & $\begin{array}{c}.91 \\
(.001)\end{array}$ & $\begin{array}{c}.33 \\
(.16)\end{array}$ \\
\hline Movie Scene & & & & 1.00 & $\begin{array}{c}.84 \\
(.001)\end{array}$ & $\begin{array}{c}.29 \\
(.22)\end{array}$ \\
\hline Speech & & & & & 1.00 & $\begin{array}{c}.47 \\
(.04)\end{array}$ \\
\hline
\end{tabular}


Table 8

Absolute Values of Diastolic Blood Pressure During Challenge Anticipation Bivariate Correlations (and $\mathrm{P}$ values)

(Two-tailed Significance)

\begin{tabular}{|c|c|c|c|c|c|c|}
\hline & Handgrip & Math & Mirror Trace & Movie & Speech & Natural \\
\hline Handgrip & 1.00 & $\begin{array}{c}.79 \\
(.001)\end{array}$ & $\begin{array}{c}.84 \\
(.001)\end{array}$ & $\begin{array}{c}.81 \\
(.001)\end{array}$ & $\begin{array}{c}.88 \\
(.001)\end{array}$ & $\begin{array}{c}.43 \\
(.06)\end{array}$ \\
\hline Math & & 1.00 & $\begin{array}{c}.85 \\
(.001)\end{array}$ & $\begin{array}{c}.80 \\
(.001)\end{array}$ & $\begin{array}{c}.86 \\
(.001)\end{array}$ & $\begin{array}{c}.54 \\
(.02)\end{array}$ \\
\hline Mirror Trace & & & 1.00 & $\begin{array}{c}.88 \\
(.001)\end{array}$ & $\begin{array}{c}.81 \\
(.001)\end{array}$ & $\begin{array}{c}.63 \\
(.003)\end{array}$ \\
\hline Movie Scene & & & & 1.00 & $\begin{array}{c}.81 \\
(.001)\end{array}$ & $\begin{array}{c}.57 \\
(.01)\end{array}$ \\
\hline Speech & & & & & 1.00 & $\begin{array}{c}.41 \\
(.07)\end{array}$ \\
\hline
\end{tabular}

Table 9

Absolute Values of Heart Rate During Challenge Anticipation Bivariate Correlations (and $\mathrm{P}$ values)

(Two-tailed Significance)

\begin{tabular}{|c|c|c|c|c|c|c|}
\hline & Handgrip & Math & Mirror Trace & Movie & Speech & Natural \\
\hline Handgrip & 1.00 & $\begin{array}{c}.92 \\
(.001)\end{array}$ & $\begin{array}{c}.89 \\
(.001)\end{array}$ & $\begin{array}{c}.88 \\
(.001)\end{array}$ & $\begin{array}{c}.89 \\
(.001)\end{array}$ & $\begin{array}{c}.53 \\
(.02)\end{array}$ \\
\hline Math & & 1.00 & $\begin{array}{c}.78 \\
(.001)\end{array}$ & $\begin{array}{c}.85 \\
(.001)\end{array}$ & $\begin{array}{c}.92 \\
(.001)\end{array}$ & $\begin{array}{c}.49 \\
(.03)\end{array}$ \\
\hline Mirror Trace & & & 1.00 & $\begin{array}{c}.94 \\
(.001)\end{array}$ & $\begin{array}{c}.82 \\
(.001)\end{array}$ & $\begin{array}{c}.56 \\
(.01)\end{array}$ \\
\hline Movie Scene & & & & 1.00 & $\begin{array}{c}.84 \\
(.001)\end{array}$ & $\begin{array}{c}.60 \\
(.01)\end{array}$ \\
\hline Speech & & & & & 1.00 & $\begin{array}{c}.46 \\
(.04)\end{array}$ \\
\hline
\end{tabular}

Correlations between laboratory challenges and the proposal/defense.

For SBP, anticipation of the math and speech challenges was significantly correlated with anticipation of the proposal/defense, $\mathrm{r}(20)=.48, \mathrm{p}=.03$, and $\mathrm{r}(20)=.47, \mathrm{p}<.04$, respectively. The correlation between SBP during anticipation of the handgrip challenge and the natural 
stressor approached significance, $\mathrm{r}(20)=.40, \mathrm{p}=.08$. DBP observed during the proposal/defense anticipation period was significantly correlated with DBP observed during the anticipation periods prior to the Mirror Trace challenge, $r(20)=.63, p=.003$, the Movie Scene challenge, $r(20)=.57, p$ $=.01$, and the Math challenge $\mathrm{r}(20)=.54, \mathrm{p}=.02$. Correlations between the proposal/defense anticipation period and the anticipation periods for the handgrip and speech challenges approached significance (p's $=.058$ and .074 , respectively). Finally, for HR, all correlations were significant between the laboratory and proposal/defense anticipation periods (r's ranged from .46 to .60). $\underline{\text { Task Periods }}$

Correlations among laboratory challenges. For SBP absolute values observed during challenge performance, all laboratory challenges were significantly intercorrelated (r's ranging from .43 - .72). For DBP, all intercorrelations were also significant (r's range from .58 - .79), with the exception of the correlation between the speech and handgrip challenges, $r(20)=.40$, $\mathrm{p}=.07$, which approached significance. Finally, during challenge performance, HR's during all laboratory challenges were significantly correlated (r's ranging from .66 - .90).

Correlations between laboratory challenges and the proposal/defense. No significant cross-session correlations were noted for SBP. However, for DBP, the speech challenge was correlated significantly with DBP during the natural stressor, $r(22)=.44, \mathrm{p}<.05)$, and the correlation between DBP during the movie scene challenge and the natural stressor approached significance, $r(22)=.41, p=.056$. Finally, both the HR during the speech challenge, $r(22)=.57$, $\mathrm{p}<.005$, and the mirror tracing challenge, $\mathrm{r}(22)=.54, \mathrm{p}<.01$, were significantly correlated with HR during the natural stressor. 
Table 10

Absolute Values of Systolic Blood Pressure During Challenge Performance Bivariate Correlations (and $\mathrm{P}$ values)

(Two-tailed Significance)

\begin{tabular}{|c|c|c|c|c|c|c|}
\hline & Handgrip & Math & Mirror Trace & Movie & Speech & Natural \\
\hline Handgrip & 1.00 & $\begin{array}{c}.58 \\
(.006)\end{array}$ & $\begin{array}{c}.66 \\
(.001)\end{array}$ & $\begin{array}{c}.67 \\
(.001)\end{array}$ & $\begin{array}{c}.43 \\
(.05)\end{array}$ & $\begin{array}{l}-.06 \\
(.80)\end{array}$ \\
\hline Math & & 1.00 & $\begin{array}{c}.65 \\
(.001)\end{array}$ & $\begin{array}{c}.72 \\
(.0001)\end{array}$ & $\begin{array}{c}.62 \\
(.002)\end{array}$ & $\begin{array}{c}.27 \\
(.22)\end{array}$ \\
\hline Mirror Trace & & & 1.00 & $\begin{array}{c}.70 \\
(.0001)\end{array}$ & $\begin{array}{c}.71 \\
(.0001)\end{array}$ & $\begin{array}{c}.06 \\
(.79)\end{array}$ \\
\hline Movie Scene & & & & 1.00 & $\begin{array}{c}.66 \\
(.001)\end{array}$ & $\begin{array}{c}.28 \\
(.21)\end{array}$ \\
\hline Speech & & & & & 1.00 & $\begin{array}{c}.21 \\
(.34)\end{array}$ \\
\hline
\end{tabular}

Table 11

Absolute Values of Diastolic Blood Pressure During Challenge Performance Bivariate Correlations (and P values) (Two-tailed Significance)

\begin{tabular}{|c|c|c|c|c|c|c|}
\hline & Handgrip & Math & Mirror Trace & Movie & Speech & Natural \\
\hline Handgrip & 1.00 & $\begin{array}{c}.58 \\
(.006)\end{array}$ & $\begin{array}{c}.59 \\
(.005)\end{array}$ & $\begin{array}{c}.64 \\
(.002)\end{array}$ & $\begin{array}{c}.40 \\
(.07)\end{array}$ & $\begin{array}{c}.18 \\
(.42)\end{array}$ \\
\hline Math & & 1.00 & $\begin{array}{c}.69 \\
(.0001)\end{array}$ & $\begin{array}{c}.79 \\
(.0001)\end{array}$ & $\begin{array}{c}.61 \\
(.003)\end{array}$ & $\begin{array}{c}.34 \\
(.12)\end{array}$ \\
\hline Mirror Trace & & & 1.00 & $\begin{array}{c}.65 \\
(.001)\end{array}$ & $\begin{array}{c}.61 \\
(.003)\end{array}$ & $\begin{array}{c}.35 \\
(.11)\end{array}$ \\
\hline Movie Scene & & & & 1.00 & $\begin{array}{c}.71 \\
(.0001)\end{array}$ & $\begin{array}{c}.41 \\
(.06)\end{array}$ \\
\hline Speech & & & & & 1.00 & $\begin{array}{c}.44 \\
(.04)\end{array}$ \\
\hline
\end{tabular}


Table 12

Absolute Values of Heart Rate During Challenge Performance

Bivariate Correlations (and P values)

(Two-tailed Significance)

\begin{tabular}{|c|c|c|c|c|c|c|}
\hline & Handgrip & Math & Mirror Trace & Movie & Speech & Natural \\
\hline Handgrip & 1.00 & $\begin{array}{c}.83 \\
(.0001)\end{array}$ & $\begin{array}{c}.86 \\
(.0001)\end{array}$ & $\begin{array}{c}.83 \\
(.0001)\end{array}$ & $\begin{array}{c}.66 \\
(.001)\end{array}$ & $\begin{array}{c}.21 \\
(.36)\end{array}$ \\
\hline Math & & 1.00 & $\begin{array}{c}.90 \\
(.0001)\end{array}$ & $\begin{array}{c}.84 \\
(.0001)\end{array}$ & $\begin{array}{c}.88 \\
(.0001)\end{array}$ & $\begin{array}{c}.34 \\
(.12)\end{array}$ \\
\hline Mirror Trace & & & 1.00 & $\begin{array}{c}.80 \\
(.0001)\end{array}$ & $\begin{array}{c}.82 \\
(.0001)\end{array}$ & $\begin{array}{c}.54 \\
(.01)\end{array}$ \\
\hline Movie Scene & & & & 1.00 & $\begin{array}{c}.71 \\
(.0001)\end{array}$ & $\begin{array}{c}.19 \\
(.39)\end{array}$ \\
\hline Speech & & & & & 1.00 & $\begin{array}{c}.57 \\
(.005)\end{array}$ \\
\hline
\end{tabular}

$\underline{\text { Residualized Change Scores - Anticipation Periods }}$

Correlations among laboratory challenges. Tables 13-15 contain correlation coefficients

using residualized change scores based on anticipation values for each of the challenges. Results

of the correlational analyses indicated a significant correlation between SBP response to

anticipation of the Math and Mirror Trace challenges, $r(20)=.66, p=.002$. No significant

correlations were noted between residualized change scores for any other laboratory challenges

based on anticipation values for either DBP or HR response.

Correlations Between Laboratory Challenges and the Proposal/Defense

No significant correlations were observed between SBP, DBP, or HR response for the laboratory challenges and the proposal/defense. For DBP response, the correlation between the speech and proposal/defense residualized change scores approached significance $r(20)=.-44$, $\mathrm{p}=.053$. 
Table 13

Systolic Blood Pressure Residualized Change Scores (Anticipation)

Bivariate Correlations (and $\mathrm{P}$ values):

(Two-tailed Significance)

\begin{tabular}{|c|c|c|c|c|c|c|}
\hline & Handgrip & Math & Mirror Trace & Movie & Speech & Natural \\
\hline Handgrip & 1.00 & $\begin{array}{l}-.16 \\
(.49)\end{array}$ & $\begin{array}{l}-.28 \\
(.20)\end{array}$ & $\begin{array}{l}-.26 \\
(.24)\end{array}$ & $\begin{array}{c}.29 \\
(.19)\end{array}$ & $\begin{array}{c}.21 \\
(.38)\end{array}$ \\
\hline Math & & 1.00 & $\begin{array}{c}.57 \\
(.005)\end{array}$ & $\begin{array}{c}.24 \\
(.27)\end{array}$ & $\begin{array}{c}.19 \\
(.40)\end{array}$ & $\begin{array}{c}.21 \\
(.38)\end{array}$ \\
\hline Mirror Trace & & & 1.00 & $\begin{array}{c}.28 \\
(.21)\end{array}$ & $\begin{array}{c}.04 \\
(.85)\end{array}$ & $\begin{array}{c}.03 \\
(.91)\end{array}$ \\
\hline Movie Scene & & & & 1.00 & $\begin{array}{c}.07 \\
(.76)\end{array}$ & $\begin{array}{c}.02 \\
(.93)\end{array}$ \\
\hline Speech & & & & & 1.00 & $\begin{array}{l}-.06 \\
(.79)\end{array}$ \\
\hline
\end{tabular}

Table 14

Diastolic Blood Pressure Residualized Change Scores (Anticipation) Bivariate Correlations (and $\mathrm{P}$ values):

(Two-tailed Significance)

\begin{tabular}{|c|c|c|c|c|c|c|}
\hline & Handgrip & Math & Mirror Trace & Movie & Speech & Natural \\
\hline Handgrip & 1.00 & $\begin{array}{l}-.06 \\
(.80)\end{array}$ & $\begin{array}{l}-.05 \\
(.84)\end{array}$ & $\begin{array}{l}-.13 \\
(.55)\end{array}$ & $\begin{array}{c}.23 \\
(.30)\end{array}$ & $\begin{array}{l}-.02 \\
(.93)\end{array}$ \\
\hline Math & & 1.00 & $\begin{array}{c}.32 \\
(.15)\end{array}$ & $\begin{array}{c}.32 \\
(.14)\end{array}$ & $\begin{array}{c}.29 \\
(.20)\end{array}$ & $\begin{array}{l}.13 \\
(.58)\end{array}$ \\
\hline Mirror Trace & & & 1.00 & $\begin{array}{l}-.13 \\
(.57)\end{array}$ & $\begin{array}{c}.10 \\
(.67)\end{array}$ & $\begin{array}{c}.32 \\
(.16)\end{array}$ \\
\hline Movie Scene & & & & 1.00 & $\begin{array}{c}.09 \\
(.69)\end{array}$ & $\begin{array}{c}.33 \\
(.15)\end{array}$ \\
\hline Speech & & & & & 1.00 & $\begin{array}{c}-.44 \\
(.053)\end{array}$ \\
\hline
\end{tabular}


Table 15

Heart Rate Residualized Change Scores (Anticipation)

Bivariate Correlations (and $\mathrm{P}$ values):

(Two-tailed Significance)

\begin{tabular}{|c|c|c|c|c|c|c|}
\hline & Handgrip & Math & Mirror Trace & Movie & Speech & Natural \\
\hline Handgrip & 1.00 & $\begin{array}{l}-.02 \\
(.944)\end{array}$ & $\begin{array}{l}-.01 \\
(.97)\end{array}$ & $\begin{array}{c}.16 \\
(.48)\end{array}$ & $\begin{array}{l}-.05 \\
(.84)\end{array}$ & $\begin{array}{c}.29 \\
(.22)\end{array}$ \\
\hline Math & & 1.00 & $\begin{array}{l}-.18 \\
(.42)\end{array}$ & $\begin{array}{l}-.09 \\
(.68)\end{array}$ & $\begin{array}{c}.09 \\
(.69)\end{array}$ & $\begin{array}{l}-.25 \\
(.30)\end{array}$ \\
\hline Mirror Trace & & & 1.00 & $\begin{array}{c}.01 \\
(.98)\end{array}$ & $\begin{array}{l}-.20 \\
(.36)\end{array}$ & $\begin{array}{c}.14 \\
(.56)\end{array}$ \\
\hline Movie Scene & & & & 1.00 & $\begin{array}{l}-.40 \\
(.07)\end{array}$ & $\begin{array}{l}-.10 \\
(.67)\end{array}$ \\
\hline Speech & & & & & 1.00 & $\begin{array}{c}-.10 \\
(.68)\end{array}$ \\
\hline
\end{tabular}

\section{$\underline{\text { Residualized Change Scores - Task Values }}$}

Correlation among laboratory challenges. Correlation coefficients using the residualized change scores for each of the challenges during challenge performance may be found in Tables 16-18. For SBP response, only the speech and mirror trace challenges were significantly correlated $\mathrm{r}(22)=.57, \mathrm{p}=.006$. For DBP response, only the math and movie challenges were significantly associated, $\mathrm{r}(22)=.55, \mathrm{p}<.01$. Finally, for HR response, the speech challenge was significantly correlated with the math challenge, $\mathrm{r}(22)=.45, \mathrm{p}<.05$, and significantly, but inversely, correlated with the handgrip challenge, $r(21)=-.45, p<.05$.

Correlations Between Laboratory Challenges and the Proposal/Defense.

Regarding the correlational analyses between the laboratory and natural stressors, no significant correlations were observed for SBP or DBP. Significant correlations were observed for $\mathrm{HR}$ response between the natural stressor and both the speech challenge, $\mathrm{r}(22)=.51, \mathrm{p}=.01$, and the mirror tracing challenge, $\mathrm{r}(22)=.53, \mathrm{p}=.01$. 
Table 16

Systolic Blood Pressure Residualized Change Scores (Challenge)

Bivariate Correlations (and $\mathrm{P}$ values):

(Two-tailed significance)

\begin{tabular}{|c|c|c|c|c|c|c|}
\hline & Handgrip & Math & Mirror Trace & Movie & Speech & Natural \\
\hline Handgrip & 1.00 & $\begin{array}{l}-.18 \\
(.44)\end{array}$ & $\begin{array}{l}-.15 \\
(.51)\end{array}$ & $\begin{array}{l}-.31 \\
(.16)\end{array}$ & $\begin{array}{l}-.42 \\
(.06)\end{array}$ & $\begin{array}{l}-.36 \\
(.11)\end{array}$ \\
\hline Math & & 1.00 & $\begin{array}{c}.15 \\
(.50)\end{array}$ & $\begin{array}{l}-.001 \\
(.99)\end{array}$ & $\begin{array}{l}.004 \\
(.98)\end{array}$ & $\begin{array}{c}.02 \\
(.92)\end{array}$ \\
\hline Mirror Trace & & & 1.00 & $\begin{array}{c}.20 \\
(.36)\end{array}$ & $\begin{array}{c}.57 \\
(.006)\end{array}$ & $\begin{array}{l}-.23 \\
(.30)\end{array}$ \\
\hline Movie Scene & & & & 1.00 & $\begin{array}{l}.13 \\
(.57)\end{array}$ & $\begin{array}{c}.12 \\
(.59)\end{array}$ \\
\hline Speech & & & & & 1.00 & $\begin{array}{c}.08 \\
(.71)\end{array}$ \\
\hline
\end{tabular}

Table 17

Diastolic Blood Pressure Residualized Change Scores (Challenge)

Bivariate Correlations (and $\mathrm{P}$ values):

(Two-tailed significance)

\begin{tabular}{|c|c|c|c|c|c|c|}
\hline & Handgrip & Math & Mirror Trace & Movie & Speech & Natural \\
\hline Handgrip & 1.00 & $\begin{array}{l}.20 \\
(.38)\end{array}$ & $\begin{array}{l}-.08 \\
(.72)\end{array}$ & $\begin{array}{c}.24 \\
(.30)\end{array}$ & $\begin{array}{l}-.03 \\
(.90)\end{array}$ & $\begin{array}{l}-.20 \\
(.38)\end{array}$ \\
\hline Math & & 1.00 & $\begin{array}{l}-.06 \\
(.78)\end{array}$ & $\begin{array}{c}.55 \\
(.01)\end{array}$ & $\begin{array}{l}.11 \\
(.61)\end{array}$ & $\begin{array}{c}.01 \\
(.95)\end{array}$ \\
\hline Mirror Trace & & & 1.00 & $\begin{array}{l}-.39 \\
(.07)\end{array}$ & $\begin{array}{c}.38 \\
(.08)\end{array}$ & $\begin{array}{c}.08 \\
(.71)\end{array}$ \\
\hline Movie Scene & & & & 1.00 & $\begin{array}{c}.22 \\
(.32)\end{array}$ & $\begin{array}{c}.11 \\
(.64)\end{array}$ \\
\hline Speech & & & & & 1.00 & $\begin{array}{c}.09 \\
(.70)\end{array}$ \\
\hline
\end{tabular}


Table 18

Heart Rate Residualized Change Scores (Challenge)

Bivariate Correlations (and $\mathrm{P}$ values):

(Two-tailed Significance)

\begin{tabular}{ccccccc}
\hline & Handgrip & Math & Mirror Trace & Math & Speech & Natural \\
\hline \multirow{2}{*}{ Handgrip } & \multirow{2}{*}{1.00} & -.39 & .16 & .37 & -.45 & -.32 \\
& & $(.08)$ & $(.50)$ & $(.10)$ & $(.04)$ & $(.15)$ \\
Math & & -.01 & -.21 & .45 & .18 \\
& & & $(.95)$ & $(.34)$ & $(.04)$ & $(.41)$ \\
Mirror Trace & & & 1.00 & .15 & .16 & .53 \\
& & & $(.50)$ & $(.48)$ & $(.01)$ \\
Movie Scene & & & 1.00 & -.20 & -.37 \\
& & & & & $(.36)$ & $(.09)$ \\
Speech & & & & & & \\
& & & & & & \\
\hline
\end{tabular}

\section{Effect of Aggregation of Measures of Cardiovascular Reactivity on}

Predicting Cardiovascular Reactivity to the Natural Setting

$\underline{\text { Step-wise Regression Analysis }}$

To investigate the hypothesis that incorporating multiple challenges would improve the prediction of cardiovascular reactivity to a naturally occurring stressor, step-wise regression was conducted using the cardiovascular reactivity to the proposal/defense as the criterion variable and the measures of cardiovascular reactivity to the five laboratory challenges as the predictor variables. In order to more closely investigate the additive effects of challenge aggregation, Tables 19-21 demonstrate the cumulative effect of incrementally adding laboratory challenges into the prediction of proposal/defense reactivity. This was accomplished by modifying the $\mathrm{p}$-in and $\mathrm{p}$-out values used in the stepwise regression analyses such that all laboratory challenges were entered into the stepwise regression equations. Because no significant correlations were observed between laboratory and natural anticipation periods, the stepwise analyses were only done on residualized change scores during task periods. 
Blood Pressure Reactivity. Results of stepwise regression analyses for both blood pressure parameters of SBP and DBP indicated that no single challenge or combination of challenges entered into the regression equation significantly predicted natural SBP or DBP reactivity (See Tables $19 \& 20$ ). Therefore, like the correlational analyses, no effect was found between a single challenge in the laboratory and the natural stressor. For SBP responses, the amount of explained variance increased from $13 \%(\mathrm{R}[21]=-.36$; handgrip) to $23.0 \%(\mathrm{R}[21]=$ .479) by incorporating the remaining four challenges. For DBP responses, the amount of variance explained by the laboratory reactivity increased only from $4 \%(R[21]=-.20)$ with only 1 laboratory challenge (handgrip) to $9 \%(\mathrm{R}[21]=.30)$ with the inclusion of the remaining challenges.

Table 19

Association Between Laboratory and Natural Reactivity Scores Stepwise Regression Equation Systolic Blood Pressure

\begin{tabular}{cccccc}
\hline & $\begin{array}{c}\text { Step \#1 } \\
\text { HG }\end{array}$ & $\begin{array}{c}\text { Step \#2 } \\
\text { HG,MI }\end{array}$ & $\begin{array}{c}\text { Step \#3 } \\
\text { HG,MI,SP }\end{array}$ & $\begin{array}{c}\text { Step \#4 } \\
\text { HG,MI,SP,MO }\end{array}$ & $\begin{array}{c}\text { Step \#5 } \\
\text { HG,MI,SP,MO,MA }\end{array}$ \\
\hline Multiple R & -.36 & .46 & .47 & .48 & .48 \\
R Square & .13 & .22 & .22 & .23 & .23 \\
F value & 2.89 & 2.47 & 1.64 & 1.19 & .90 \\
Sig of F & .11 & .11 & .22 & .35 & .51 \\
\hline
\end{tabular}

* No laboratory challenges entered into stepwise regression equation predicting proposal/defense reactivity

Table 20

Association Between Laboratory and Natural Reactivity Scores Stepwise Regression Equation Diastolic Blood Pressure

\begin{tabular}{cccccc}
\hline & $\begin{array}{c}\text { Step \#1 } \\
\text { HG }\end{array}$ & $\begin{array}{c}\text { Step \#2 } \\
\text { HG,MO }\end{array}$ & $\begin{array}{c}\text { Step \#3 } \\
\text { HG,MO,MI }\end{array}$ & $\begin{array}{c}\text { Step \#4 } \\
\text { HG,MO,MI,MA }\end{array}$ & $\begin{array}{c}\text { Step \#5 } \\
\text { HG,MO,SP,MI,MA }\end{array}$ \\
\hline Multiple R & -.20 & .26 & .29 & .30 & .30 \\
R Square & .04 & .07 & .08 & .09 & .09 \\
F value & .80 & .64 & .52 & .39 & .30 \\
Sig of F & .38 & .54 & .67 & .82 & .91 \\
\hline
\end{tabular}

* No laboratory challenges entered into stepwise regression equation predicting proposal/defense reactivity 
Heart Rate Reactivity. In contrast to the blood pressure findings, heart rate reactivity measured in the laboratory did predict heart rate reactivity in the natural setting. The relation was significantly improved when aggregating across multiple laboratory challenges. As shown in Table 22 , this analysis revealed that the reactivity associated with the movie scene and mirror trace challenges entered into the regression equation predicting proposal/defense reactivity, resulting in a multiple $\mathrm{R}$ of .70 and an $\mathrm{R}$ square of .49 versus a multiple $\mathrm{R}$ of .52 and an R Square of .27 for the movie challenge alone. The speech challenge reactivity narrowly missed inclusion in the regression equation as its significance level of $.053 \mathrm{did}$ not meet the $\mathrm{p}$-in criteria of .05 . Had this variable been included, the $\mathrm{R}$ value and amount of explained variance would have further increased to .77 and .59 , respectively. The addition of the handgrip and math challenges did not significantly further improve prediction of the proposal/defense reactivity.

Table 21

Association Between Laboratory and Natural Reactivity Scores

Stepwise Regression Equation

\begin{tabular}{cccccc}
\multicolumn{7}{c}{ Heart Rate } \\
& $\begin{array}{c}\text { Step \#1 } \\
\text { MO* }\end{array}$ & $\begin{array}{c}\text { Step \#2 } \\
\text { M0,MI* }\end{array}$ & $\begin{array}{c}\text { Step \#3 } \\
\text { MO,MI,SP }\end{array}$ & $\begin{array}{c}\text { Step \#4 } \\
\text { MO,MI,SP,HG }\end{array}$ & $\begin{array}{c}\text { Step \#5 } \\
\text { MO,MI,SP,HG,MA }\end{array}$ \\
\hline Multiple R & .52 & .70 & .77 & .78 & .78 \\
R Square & .27 & .49 & .59 & .60 & .61 \\
F value & 7.09 & 8.70 & 8.30 & 6.11 & 4.67 \\
Sig of F & .015 & .002 & .008 & .003 & .009 \\
\hline
\end{tabular}

* Movie Scene and Mirror Trace challenges entered into a stepwise regression equation predicting proposal/defense reactivity

\section{Intraclass Correlational Analyses}

Bivariate correlational analyses based on residualized change scores (employing challenge responding) were conducted separately for each cardiovascular parameter between each of the laboratory challenges and the proposal/defense for stereotypic and non-stereotypic participants. See Table 22 for Pearson R values and significance levels. 


\section{$\underline{\text { Systolic Blood Pressure }}$}

For SBP response, responses from neither group demonstrated significant correlations between four of the lab challenge-proposal/defense pairings. However, the stereotypic group demonstrated a significant correlation between the movie scene and proposal/defense, $\mathrm{r}(10)=.69$, $\mathrm{p}=.02$, whereas this correlation for the nonstereotypic group did not reach significance. The difference between these independent correlations approached significance $(\mathrm{z}=1.92, \mathrm{p}=.06)$.

\section{Diastolic Blood Pressure}

For DBP response, responses from neither group demonstrated significant correlations between the laboratory challenges and the proposal/defense.

\section{$\underline{\text { Heart Rate }}$}

For HR response, there were three laboratory challenge-proposal/defense pairings in which one of the two groups demonstrated a significant correlation while the other group did not. The stereotypic group exhibited a significant inverse correlation between HR response to the proposal/defense and the handgrip $\mathrm{r}(10)=-.82, \mathrm{p}=.04$, as well as a significant direct correlation between HR response to the proposal/defense and the speech challenge, $r(10)=.64, p=.03$, while the non-stereotypic group exhibited a significant correlation between the HR response to the proposal/defense and the mirror trace challenge, $r(10)=.71, p=.02$. The difference between the $r$ values for the two groups based on HR responding during the handgrip challenge was significant $(\mathrm{z}=2.05, \mathrm{p}<.05)$, but not during the mirror tracing or speech challenges ( $\mathrm{z}$ 's $=.75$ and .90 , respectively). 
Table 22

Laboratory Challenge and Proposal/Defense Bivariate Correlations and (P values): Residualized Change Scores (Two-tailed Significance)

\begin{tabular}{ccccccc}
\hline & \multicolumn{2}{c}{ Systolic } & \multicolumn{2}{c}{ Diastolic } & \multicolumn{2}{c}{ Heart Rate } \\
& Stereotypic & Nonstereotypic & Stereotypic & Nonstereotypic & Stereotypic & Nonstereotypic \\
\hline \multirow{2}{*}{ Handgrip } & .35 & -.46 & -.41 & -.26 & -.82 & -.13 \\
& $(.32)$ & $(.16)$ & $(.24)$ & $(.44)$ & $(.004)$ & $(.71)$ \\
Math & .17 & -.12 & .16 & -.18 & -.26 & .34 \\
& $(.62)$ & $(.73)$ & $(.64)$ & $(.59)$ & $(.44)$ & $(.30)$ \\
Mirror Trace & .12 & -.27 & -.19 & .23 & .47 & .71 \\
& $(.72)$ & $(.42)$ & $(.58)$ & $(.49)$ & $(.15)$ & $(.02)$ \\
Movie Scene & .69 & -.11 & .38 & -.01 & .04 & -.59 \\
& $(.02)$ & $(.74)$ & $(.25)$ & $(.97)$ & $(.90)$ & $(.07)$ \\
Speech & .04 & .25 & -.12 & .32 & .64 & .30 \\
& $(.91)$ & $(.46)$ & $(.73)$ & $(.34)$ & $(.03)$ & $(.37)$ \\
\hline
\end{tabular}

\section{DISCUSSION}

\section{Overview}

Although cardiovascular reactivity to stress has been proposed as a potential risk factor in predicting coronary artery disease, it has been met with skepticism and limited acceptance due to limitations and criticisms associated with methodological imprecision (e.g., Pickering, 1995;

Parati et al., 1991). While previous work has demonstrated that cardiovascular response to stress possesses adequate temporal and cross-task stability (Kasprowicz et al., 1988; Ward et al., 1994; Bunnell, 1982), the evidence thus far has been less supportive with regard to the generalization of findings obtained in laboratory settings to field or "real life" cardiovascular responding (Turner et al., 1990; Warwick-Evans et al., 1988). The goal of this study was to investigate cardiovascular responding within a multi-task laboratory setting as well as the effect of laboratory challenge aggregation in predicting "real life" cardiovascular responding to a naturally occurring stressor. 
Results from this investigation clearly demonstrate that the degree of cardiovascular response to the defense or proposal of a thesis or dissertation is much greater than that observed in response to any of the five laboratory challenges. Partially supported was the hypothesis that the use of a laboratory-based multi-task methodology would significantly improve the ability to predict cardiovascular reactivity to stress in a natural setting. Not supported by this investigation was the hypothesis that the cardiovascular reactivity associated with the speech challenge would demonstrate the greatest correlation with the proposal/defense as compared to the four other laboratory challenges. In addition to the proposed hypotheses, two supplemental analyses were also conducted. First, consistently higher correlations were observed among the laboratory challenges and the proposal/defense using absolute values measured during anticipatory period versus task periods, though this pattern was not observed when analyzed using residualized change scores. Second, participants' levels of response stereotypy did not appear to play a significant role in systematically influencing correlations between the laboratory challenges and the proposal/defense.

\section{Cardiovascular Response Differences Across Tasks}

As predicted, the degree of observed cardiovascular reactivity was greatest in response to the natural stressor for all three cardiovascular parameters (i.e., SBP, DBP, and HR) in comparison to the five laboratory challenges. In addition to being significantly greater than all laboratory challenges based on absolute value of change from preceding rest period to the ensuing task period, this was also the case when assessed by means of percent change from baseline. For example, for all of the laboratory challenges across all three cardiovascular parameters, the percent increase from rest period to challenges ranged from $3 \%$ to $24 \%$, while the degree of change from rest period to the proposal/defense ranged from $26 \%$ (DBP \& SBP) to 
$66 \%(\mathrm{HR})$. Based upon these results it is clear that the defense or proposal of a thesis or dissertation elicited greater cardiovascular reactivity than the laboratory-based challenges, and more than likely, was perceived by participants to be a more stressful event than the five laboratory challenges. Additionally, while the degree of change in the cardiovascular parameters measured in the laboratory setting is commensurate with previous studies investigating cardiovascular reactivity to stress (Abel \& Larkin, 1991; Turner et al., 1990), the BP and HR change associated with the anticipation and performance of the proposal/defense in this study was greater than that observed in other studies investigating laboratory-to-life correspondence (Doornen et al., 1992; Abel et al., 1991). For example, though employing naturally occurring challenges similar in meaning and importance as a thesis or dissertation defense or proposal, change scores based on anticipation levels of a speech challenge (van Doornen et al., 1992), and for DBP and HR change scores in anticipation of a musical performance (Abel et al., 1991) were smaller than cardiovascular responses in the current study. SBP change, however, based on anticipation levels to the musical performance was reportedly greater in the study by Abel et al. (1991) than the current study. Finally, compared to previous studies employing ambulatory monitoring of cardiovascular reactivity to a specific stressor, HR reactivity observed in this study was much greater. For example, Turner et al. (1990) observed a 43\% increase in HR from baseline to "real world" challenge levels (68 to $97 \mathrm{bpm}$ ), and Turner et al. (1987) showed a maximum 47\% (68 to $101 \mathrm{bpm}$ ) increase in HR from baseline to "real world" responding among participants defined as "high reactors." These HR increases are notably smaller than the average $66 \%$ increase observed in the present study (67 to $112 \mathrm{bpm}$ ). However, although both of Turner's studies employed a speech challenge as the natural stressor, the consequences of these challenges were not likely as important as one's thesis or dissertation meeting. 
While there were no significant differences between rest periods for either SBP or DBP, significant differences were observed when comparing resting HR levels (HR prior to handgrip challenge $>$ HR prior to math, speech, and final rest periods; HR prior to math challenge $<$ HR prior to mirror trace and movie scene challenges). Although these differences were significant, the magnitude of these differences was quite small (less than $3 \mathrm{bpm}$ ). Given that the presentation of the laboratory challenges was counter-balanced and that participants were not made aware of the challenges prior to the anticipation periods, it is improbable that these findings were influenced by any anticipatory effects. Regardless, any influence of baseline differences was removed through the use of residualized change scores.

\section{Relations Between Laboratory Challenges and the Proposal/Defense}

Not supported by this study was the prediction that of the five laboratory challenges, the cardiovascular reactivity associated with the speech challenge would show the greatest correlation with the cardiovascular reactivity associated with the proposal/defense. While the difference in association with the proposal/defense between the speech and mirror trace challenges was essentially indistinguishable based on heart rate ( $\mathrm{r}$ 's $=.51 \mathrm{vs} .53$, respectively), blood pressure reactivity (both SBP and DBP) associated with the speech challenge showed minimal association with the proposal/defense reactivity. More specifically, for SBP and DBP responding, the $\mathrm{r}$ values did not even exceed .10 for the speech challenge, while the reactivity associated with the handgrip challenge demonstrated the greatest correlation (though negative) with the proposal/defense reactivity for both of these parameters at -.36 and -.20 , respectively. It is interesting to note this lack of association in light of the fact that the speech challenge, in addition to strongly resembling the natural stressor, elicited the greatest degree of change from resting levels for all three cardiovascular parameters among the five laboratory challenges. 
When investigating the association between the laboratory challenges and the proposal/defense based on levels of absolute values of cardiovascular measures observed during the challenges, however, a different picture emerges. Based on this data, the speech challenge demonstrated the greatest correlation with the proposal/defense for both DBP and HR (r's $=.44$ and .57 , respectively), and the degree of association between the speech and the proposal/defense for SBP was .21. It appears then, that similarity of task characteristics increases correlations between challenges when using absolute values but not residualized change scores. This finding is consistent with previous work demonstrating greater correlations among laboratory-to-life comparisons based on baseline and task levels versus reactivity scores (Light, Turner, Hinderliter, \& Sherwood, 1993; Fredrikson et al., 1990; Ironson, Gellman, Spitzer, et al., 1989). In addition, measures based on absolute values in the present study demonstrated somewhat higher generalizability during anticipation periods than during task responding. This is also consistent with previous work demonstrating greater levels of correspondence among readings taken when participants are not engaged in tasks or challenges, such as during baseline or anticipation periods. This suggests that cardiovascular responding may be more stable when the participant is not engaged in challenge performance, perhaps due to differential verbal or motoric influences that occur during challenge performance. It may also be that structural, or topographic similarity between compared challenges is less important than other features of the challenges such as type and intensity of emotional responding. More specifically, the emotional responses most likely elicited by the movie scene (e.g., fear, anxiety) are very similar to those most likely experienced during the defense or proposal of a thesis or dissertation, challenges in which the participant has much at stake. For example, based on residualized change scores, the reactivity associated with the movie scene challenge demonstrated the greatest positive correlation 
with the reactivity associated with both blood pressure parameters $(\mathrm{SBP}=.12, \mathrm{DBP}=.11)$ than all other challenges.

Few differences in laboratory-to-life generalizability emerged between groups designated as demonstrating either high or low levels of response stereotypy; therefore, there appear to be few significant differences in cardiovascular reactivity related to consistency of responding across multiple challenges. High stereotypic participants did not evidence consistently different relations between laboratory and natural settings than low stereotypic participants. However, these findings must be interpreted with caution. Since the primary purpose of this study was not to examine stereotypy, the high stereotypy group was a mixed group of HR stereotypic and BP stereotypic responders. Had a larger group of BP or HR stereotypic responders been identified, the findings may have been quite different. Future studies are needed to examine the relation between stereotypy and laboratory-to-life generalization of cardiovascular reacativity.

\section{Aggregation of Laboratory Challenges and Proposal/Defense Cardiovascular Response}

Less conclusive evidence was found for the hypothesis that a multi-task methodology would significantly improve the prediction of cardiovascular reactivity occurring in response to a "real life" event. Stepwise regression analyses demonstrated a statistically significant additive effect, but only for HR responding. It should be noted that the use of a stepwise regression equation is somewhat atypical of aggregation methods used in other studies, in which the multiple sources of variance are all added together at once, rather than sequentially. However, these results do show similarities to previous research investigating the effect of task aggregation. First, the degree of change observed by incorporating multiple task aggregation was commensurate with, or greater than that reported in a collection of five previous investigations conducted by Manuck et al. (1993), in which the mean R increases for SBP, DBP, and HR with 
multiple tasks were $8 \%, 9 \%$, and $7.6 \%$, respectively. Second, the pattern of test-retest

correlations obtained in the present study is identical to that which has been previously reported in the literature (Manuck et al., 1993; Kasprowicz, Manuck, Malkoff, \& Krantz, 1990); heart rate responses show the greatest reliability, and blood pressure responses, especially DBP, show the least reliability. Three possible factors that may contribute to this pattern in the current study include the relatively young age and low body weight of the participants, as well as their high average amount of exercise per week. Previous work has demonstrated lower blood pressure testretest correlations among younger and lower weight samples in response to stress (Kate et al, 1980; Prineas, Gillum, Horibe, \& Hannan, 1980; Johnson et al., 1975), as well as among persons without morphologic manifestations of CHD (e.g., intimal thickening of the coronary arteries; Pesonen et al, 1990).

Several hypotheses have been proposed which specifically attempt to account for lower consistency associated with DBP responding to stress observed in this study as well as previous studies. First, of the three measures, DBP is determined by more complex factors (e.g., vasomotor control of microcirculation of blood through the various tissues and organs of the body), thus decreasing the likelihood of consistent response to stressors. Support for this contention is provided by Sherwood et al. (1990) who observed that DBP response is determined by the complex interaction of changes in vascular and myocardial activity and "therefore will demonstrate a level of stability limited by that for both of these factors combined" (p. 97). Second, as also pointed out by Sherwood et al. (1990), greater measurement error associated with DBP may lower reproducibility. More specifically, it has been suggested that it is more difficult to determine the absence of a sound (as is required to determine DBP) than it is to determine the appearance of a sound (as determines SBP). Finally, the smaller magnitude of 
change in DBP response to stressors is a factor; correlations tend to be smaller when observed values are restricted to a smaller range (Gravlee \& Brockschmidt, 1990; Sherwood et al., 1990).

A review of the stepwise regression equation predicting heart rate reactivity indicates that, in the context of the four other laboratory challenges, the HR reactivity associated with the movie challenge contributed the greatest amount of unique variance to the prediction of the proposal/defense HR reactivity. This occurred despite the fact that when considered individually it ranked as only the third highest correlation in predicting the proposal/defense reactivity. Perhaps more interestingly, the speech challenge, the laboratory challenge most similar to the proposal/defense in behavioral topography and which had a greater simple correlation with the natural stressor than the movie challenge, did not add significantly to the stepwise regression equation beyond the variance accounted for by the movie and mirror trace challenges. The ability of the HR reaction to the mirror trace challenge to contribute significantly to the prediction of the HR reaction to the proposal/defense may be related to challenge characteristics which were complementary, but not redundant, with the movie challenge. For example, the movie challenge can be characterized as a passive coping task, eliciting a fearful emotional response requiring minimal physical exertion. In contrast, the mirror trace challenge can be characaterized as an active coping task which elicits little fear and requires some degree of physical activity. Because the speech challenge is also an active coping task, it may provide information regarding HR response redundant with that already accounted for by the mirror trace challenge. Further, while all laboratory challenges were completed by participants with the instructions that their performance was being evaluated, it is unlikely that any of these laboratory stressors other than the movie scene elicited a significant fear response similar to that which would be experienced in anticipation of, and during the proposal or defense meeting. This is largely because all of the 
participants knew the experimenter, and as graduate students, were likely experienced in giving oral presentations. The degree of distress experienced by study participants in response to the laboratory challenges was likely less than what would be experienced by the population at large who might approach the laboratory assessment as a more novel experience.

Low correlations between specific laboratory challenges and the natural stressor were predominant using both absolute challenge levels and residualized change scores, as the use of absolute challenge levels resulted in only three significant lab-life correlations among all three cardiovascular parameters, while the latter resulted in only two significant pairings. These findings are similar to those reported in previous research (Turner et al., 1990). For example, Turner et al. found a maximum correlation of .23 (SBP) between laboratory-based mental arithmetic and speech challenges in predicting a simulated speech challenge, as compared to a maximum correlation of .53 (HR) between laboratory and field challenges in the present study. In addition, 5 other laboratory-field correlations in the present study equalled or exceeded the maximum value reported by Turner et al.

\section{Limitations of the Study}

The following factors raise concern regarding the generalizability of these findings. First, the relatively small sample size limited the power to detect significant differences that may have emerged within a larger pool of participants. For example, given the strength of the associations between the proposal/defense and the handgrip and mirror trace challenges in the SBP stepwise regression, and between the natural and speech challenges in the HR stepwise regression, it is possible that the inclusion of more participants would have revealed a broader pattern of individual differences in cardiovascular responding as well as stronger effects in the stepwise 
regression equations for both of these cardiovascular parameters. This possibility must be considered with caution, however, due to the low power resulting from the small sample size.

A second possible limitation concerns the a priori relationship between the experimenter and the participants, as all of the participants were familiar with the experimenter. For example, the demands of the laboratory setting may have been less threatening due to this familiarity as opposed to a sample of undergraduate students or medical patients not familiar with the experimenter. Additionally, psychology graduate students have a much greater awareness of factors related to the methods of investigation, and may therefore have been less affected by instructions that their performance on the laboratory measures would be closely evaluated. Anecdotal evidence, however, suggests that most participants did not disregard the instruction that performance on the laboratory challenges was being closely evaluated.

A third issue also concerns the characteristics of the sample that was investigated. Similar to the samples reported in the six previously reviewed studies that investigated cardiovascular reactivity to a specific field stressor, this was a young sample; all participants were characterized as "healthy," the sample pool was drawn from an academic setting, and four of these six studies also employed a mixed gender sample. Although it could be argued that the "robustness" of the significant findings in this study are accentuated by the fact that this was a very young and healthy sample, it also may be that the inability to detect significant laboratory - life correlations using reactivity scores is a reflection of the overall cardiovascular health of this sample. Given the participants' average age of 28 years, that the average weekly exercise amount was greater than three hours, and that only two of the twenty-two (9\%) reported tobacco use, this higher level of cardiovascular and aerobic fitness may have attenuated the participants' blood pressure and heart rate responses to the laboratory challenges. As noted previously, correlations tend to be smaller 
when observed values are restricted to a smaller range. Second, this was a mixed gender sample comprised of sixteen women and six men, and there is some research that has demonstrated significant gender differences in cardiovascular patterns and reactivity to stress (e.g., Shapiro, Goldstein, \& Jamner, 1995). Gender differences that have been reported include lower BP levels among women than men until shortly after onset of menopause (Boyle, Griffey, Nichaman, \& Talbert, 1967), and the tendency to show a less pronounced cardiovascular responsivity to stress as compared to men (Frankenhauser, 1983). Also, men have been shown to show more consistency in laboratory-field comparisons than women (Fredrickson, 1990). In addition, previous research has shown both HR and BP reactions among women can differ between phases of the menstrual cycle (Hastrup, Light, \& Obrist, 1979), implicating the effect of hormonal fluctuations on cardiovascular responding to behavioral stressors, although these findings are not robust. Therefore, obtaining information regarding the menstrual status of female participants at the time of psychophysiologic assessment may provide valuable data to further elucidate the impact of this factor associated with gender differences in cardiovascular reactivity. Regardless, since a mixed gender sample of predominantly women was employed, it is unknown what lab-tolife generalizability would be observed in male only or female only samples.

Fourth, the cardiovascular levels obtained during the final rest period of the laboratory assessment served as the baseline score in determining the proposal/defense reactivity, as it was impossible to obtain baseline measurements in the participants' natural setting during the day of the defense or proposal meeting. The use of this rest period appeared justified, however, for the following reasons. First, as it was the final rest period taken after completion of all of the laboratory challenges, anticipation/expectancy effects were minimized. Second, there were no 
significant differences among the rest periods for either of the BP parameters, and in the only comparison that reached significance (i.e., HR responding), the final rest period levels were less than the resting HR level occurring before some other challenges (e.g., handgrip). Third, it is highly unlikely that levels obtained in the hour preceding the proposal or defense meeting could be characterized as true baseline levels due to their temporal proximity to the stressful event. However, one could argue that the proposal/defense reactivity scores were a "mixed product" comprised of both laboratory and "real life" data, and thus not a pure measure of cardiovascular reactivity associated with a natural occurring event. Optimally, measures of cardiovascular functioning would be obtained while participants slept at night in order to provide a "true," and likely more standardized, baseline with which reactivity measures would be calculated. This is supported by previous work by Pollack (1991) in which reactivity scores based on baseline measures obtained in the laboratory failed to yield significant associations with ambulatory variables, though laboratory reactivity scores based on "minimum heart rate during sleep" were significantly associated with ambulatory responding.

Finally, the characteristics of the naturally occurring stressor chosen for this study may also have limited the generalizability of these findings. Though the proposal or defense of a thesis or dissertation obviously resulted in significant cardiovascular activation, this high degree of arousal is not likely to be experienced frequently enough in everyday life to have a significant continuous effect on the cardiovascular system. Stated more simply, while this was a "real life" event, it is most likely not representative of the type and intensity of demands experienced by most people, on most days of their lives. Therefore, while accurately characterized as "naturally occurring," this stressor is not a "natural" stressor in the daily lives of the participants. As such, this criticism may be extended to the majority of other lab-to-life investigation of cardiovascular 
reactivity to specific field stressor. Of the six previously mentioned studies employing such a methodology, two others also utilized proposal/defense-type stressors (van Doornen \& van Blokland, 1992; Abel \& Larkin, 1991), while the remaining four employed either public speaking (Matthews, et al., 1986; Turner, et al., 1987; Turner, et al., 1990) or academic examinations (Warwick-Evans, et al., 1988). In addition, it was not possible to standardize many aspects of this event that may have varied significantly among the participants. For example, although the type of "real life" event experienced by all participants was similar in structure and meaning (i.e., progression towards their degree), the members of each participants examining committee were different. Additionally, there likely existed differences in intensity of feelings of confidence and/or perceived threat experienced by the participants. Further, no attempt was made to standardize or control for whether participants were sitting or standing during the measurement period in the proposal or defense meeting, and postural effects have been shown to significantly affect blood pressure (Light et al., 1993; Turner \& Sherwood, 1991). Finally, though participants were informed to refrain from use of stimulants the hours immediately preceding both the laboratory and natural assessments, no information was obtained regarding the use of such substances the evening prior to these assessments. However, some degree of standardization was obtained by taking readings during the first four minutes of the participant's presentation: this aspect of situation was in the control of the participant, he/she had rehearsed their presentation, and no questions were asked of them during this time period.

\section{Future Directions}

Despite the voluminous and extensive literature investigating cardiovascular reactivity to stress, there exists relatively little consensus regarding the standardization of methodologies of investigation. Although the effects of protocol standardization have led toward improvements in 
generalizability (Manuck et al., 1994; McKinney et al., 1985), there is still no consistency in such a basic issue as to how define reactivity itself. For example, baseline levels used in change scores have been obtained on days free of anticipatory or demand effects (e.g., Turner et al., 1987), but also on the same day as laboratory assessment (e.g., Abel et al., 1991), either prior to any of the laboratory challenges, before each specific challenge, or at the completion of laboratory assessment. Likewise, indices of change have incorporated the arithmetic difference between task and baseline levels (e.g., Warwick-Evans et al., 1988), covariance-based techniques, such as residualized change scores (e.g., Abel et al., 1991), and range of responding, such as variability (e.g., Steptoe et al., 1984). These methodologic inconsistencies diminish the ability to identify and develop areas of consensus regarding the most basic aspects of the reactivity hypothesis. Perhaps prospective, longitudinal studies investigating the ability of the various reactivity scores to predict cardiovascular disease would provide a heuristic rationale for which of the many definitions to use.

The preponderance of studies investigating the generalizability of cardiovascular reactivity in "lab-life" settings have relied on small sample sizes with very homogenous characteristics (i.e., young, healthy students). While such samples are convenient and valid for the purposes of initial hypothesis generation and testing, findings from these investigations suffer in generalizability, and do not allow for the elucidation of possible differences related to such factors as gender, race, and socio-economic status; i.e., demonstrations of the generalizability of cardiovascular reactivity in young, Caucasian college students, does not guarantee that such relations exist among other potential samples. As such, the robustness of the reactivity hypothesis is lacking, and would be improved by replication studies focusing on a broader range of participant samples allowing for a more detailed delineation of interactions between participant characteristics, methodological issues (i.e., task influences on cardiovascular reactivity), and health outcomes. 
In addition to increasing the range of participant characteristics, this area would also benefit from greater use of impedance cardiography in order to understand more closely hemodynamic reactions to behaviorally-evoked pressor responses. This technology allows for the assessment of both forces accounting for blood pressure: cardiac output and peripheral resistance. Previous work has already demonstrated that these indices of cardiovascular function possess adequate test-retest reliability (Kasprowicz, et al., 1990; Saab, et al., 1992), as well as strong intertask consistency in response to behavioral challenges sufficient to be characterized as a stable individual difference variable (Sherwood, et al., 1992). The ability to monitor the basic components of blood pressure (cardiac output and peripheral resistance) may identify significant relations heretofore masked by the composite nature of diastolic and systolic BP readings. For example, it may be that changes of a certain magnitude in peripheral resistance are consistently associated with certain laboratory challenges, though offsetting changes in cardiac output may "neutralize" this effect.

Although studies investigating the relations between cardiovascular reactivity to specific laboratory challenges and "real life" events are a necessary step in developing the psychometric qualifications required to support reactivity as a reliable individual difference variable, research to date has focused exclusively on reactivity to either specific, discreet natural events or have monitored cardiovascular parameters during extended periods involving a wider range of activities. Given that findings based on each of these strategies have demonstrated only minimal stability, and that cardiovascular reactivity is most likely to have its effect on the development of cardiovascular disease through increased reactivity to a variety of classes of stimuli across time, it may now be appropriate to design assessments more consistent with the types of stressors encountered in daily life. One such proposal has been made by Sausen et al. (1992), with their suggestion that future efforts consider a "controlled occupational stressor" paradigm combining 
features of both approaches. Such an approach would have the ecological advantage of monitoring cardiovascular functioning throughout a full day, along with the methodological contribution afforded by uniformly exposing all participants to a stressor of major personal significance.

Finally, given the large disparity between change scores associated with the proposal/defense as compared to those observed in response to the laboratory challenges, it may be that the utility of the "standard" laboratory stressors should be questioned. While the breadth and type of "real life" stressors investigated has been expanding (in large part due to the advent and convenience of ambulatory monitoring), little effort has been undertaken to identify novel laboratory procedures that correlate well with naturally occuring events. Developing a more diverse array of "predictor" tasks may play an integral role in improving correlations among reactivity measures of cardiovascular function.

Although a solid foundation of support has already been demonstrated with regard to the temporal and cross-task stability of cardiovascular reactivity to stress, recent evidence has been less supportive with regard to the reliability of "laboratory-to-life" assessments of reactivity. Findings from the present study provide some evidence supportive of one means of improving the ability to predict "real-life" HR reactivity based on cardiovascular reactivity observed during laboratory assessment, namely by aggregating reactivity to multiple tasks. Though limited to HR reactivity, these are the first findings demonstrating the utility of multi-task aggregation in predicting cardiovascular reactivity measured during a specific "real life" event occuring in the "real world." Continued improvements in the assessment and measurement of cardiovascular reactivity to stress may enhance the understanding of factors related to the development of CHD, as well as in identifying persons at greater risk for heart disease. This, in time, could result in improvements in primary prevention programs aimed at reducing prevalence and incidence of CHD. 


\section{References}

Abel, L.J., \& Larkin, K.T. (1991). Assessment of cardiovascular reactivity across laboratory and natural settings. Journal of Psychosomatic Research, 35, 365-373.

American Heart Association. (1989). Heart Facts. Dallas: American Heart Association

Ax, A.F. (1953). The physiological differentiation between fear and anger in humans. Psychosomatic Medicine, 15, 433-442.

Barefoot, J.C., Dahlstrom, W.C., \& Williams, R.B. (1983). Hostility, coronary heart disease incidence, and total mortality: A 25-year follow-up study of 255 physicians. Psychosomatic Medicine, 45, 59-63.

Blackburn, H., \& Jacobs, D. (1984). Sources of the diet-heart controversy: Confusion over population vs. individual correlations. Circulation, 70, 775-780.

Blumenthal, J.A., Williams, R.S., Williams, R.B., \& Wallace, A.G. (1980). Effects of exercise on the Type A (coronary-prone) behavior pattern. Psychosomatic Medicine, 42, 289-296.

Boyle, E., Griffey, W.P., Nichaman, M.Z., \& Talbert, C.R. (1967). An epidemiologic study of hypertension among racial groups of Charleston County, S.C. The Charleston Heart Study, Phase II. In J. Stamler, R. Stamler, \& T.N. Pullman (Eds.), The epidemiology of hypertension (pp. 193-203). New York: Grune \& Stratton.

Brand, RJ, Rosenman, R.H., Sholtz, R.I., \& Friedman, M. (1976). Multi variate prediction of coronary heart disease in the Western Collaborative Group Study compared to the findings of the Framingham Study. Circulation, 53, 348-355.

Banal, DE (1982). Autonomic myocardial influences as a factor determining inter-task consistency of heart rate reactivity. Biological Psychology, 19, 81-93. 
Coronary Heart Disease. (1992). Coronary Heart Disease: A Behavioral Perspective. Champaign, IL: Research Press.

Corse, C.D., Manuck, S.B., Cantwell, J.D., Giordani, B., \& Matthews, KA (1982). Coronary-prone behavior pattern and cardiovascular response in persons with and without coronary heart disease. Psychosomatic Medicine, 44, 449-459.

Dembroski, T.M., \& Costa, P.T. (1988). Assessment of coronary-prone behavior: A current overview. Annals of Behavioral Medicine, 10, 64-70.

Ekman, P., Levenson, R.W., \& Friesen, W.V. (1983). Autonomic nervous system activity distinguishes among emotions. Science, 221, 1208-1210.

Emmons, KM, \& Weidner, G. (1988). The effects of cognitive and physical stress on cardiovascular reactivity among smokers and oral contraceptive users. Psychophysiology, 25, 166- 171.

Faultisch, M.E., Williamson, D.A., McKenzie, S.J., Dutchman, E.G., Hutchinson, KM, \& Bouin, D.C. (1986). Temporal stability of psychophysiological responding: A comparative analysis of mental and physical stressors. International Journal of Neuroscience, 30, 65-72.

Floras, J.S.D., Osman Hassal, M., Jones, JV, \& Sleight, P. (1987). Pressor responses to laboratory stresses and daytime blood pressure variability. Journal of Hypertension, 5, 715-719.

Frankenhauser, M. (1983). The sympathetic-adrenal and pituitary-adrenal response to challenge: Comparison between sexes. In T. Dembroski, T. Schmidt, \& G. Blumchen (Eds.), Biobehavioral bases of coronary heart disease (pp. 91-105). Basel: Karger.

Fredrikson, M., Blumenthal, J.A., Evans, D.D., Sherwood, A., \& Light, K.C. (1989). Cardiovascular responses in the laboratory and in the natural environment: Is blood pressure reactivity to laboratory-induced mental stress related to ambulatory blood pressure during everyday life? Journal of Psychosomatic Research, 33, 753-762. 
Friedman, M. \& Rosenhan, R.H. (1959). Association of specific over behavior pattern with blood and cardiovascular findings: Blood cholesterol level, blood clotting time, incidence of arcus senillis and clinical coronary artery disease. Journal of the American Medical Association, 169, 1286-1296.

Gerin, W., Christenfeld, N., Pieper, C., DeRafael, D., Su, O., Stroessner, S., Deich, J., \& Pickering, T. (1998). The generalizability of cardiovascular responses across setting. Journal of Psychosomatic Research, 44(2), 209-218.

Green, B.F. (1981). A primer of testing. American Psychologist, 36, 1001-1011.

Gravlee, G.P., \& Brockschmidt, J.K. (1990). Accuracy of four indirect methods of blood pressure measurement with hemodynamic correlations. Journal of Clinical Monitoring, 6, 284-298.

Hastrup, J.L., Light, K.C., \& Obrist, P.A. (1979, April). Family history of cardiovascular disorders as a predictor or individual differences in response to stress. Paper presented at the meeting of Eastern Psychological Association, Philadelphia, PA.

Haynes, S.G., Feinleib, M., \& Kannel, W.B. (1980). The relationship of psychosocial factors to coronary heart disease in the Framingham study, III: Eight year incidence of coronary heart disease. American Journal of Epidemiology, 3, 37-58.

Holroyd, KA, \& Gorkin, L. (1983). Young adults at risk for hypertension: Effects of family history and anger management in determining responses to interpersonal conflict. Journal of Psychosomatic Research, 27, 131-138.

Ironson, G.H., Gellman, M.D., Spitzer, S.B., Llabre, M.M., Pasin, R., Weidler, D.J., \& Schneiderman, N. (1989). Predicting home and work blood pressure measurements from resting baseline and laboratory reactivity in black and white Americans. Psychophysiology, 26, 174-184. 
James, G.D., Pickering, T.G., Yee, L.S., Harshfield, G.A., Riva, S., \& Laragh, J.H.

(1988). The reproducibility of average ambulatory, home, and clinic pressures. Hypertension, 11 , $545-549$.

Jeffrey, R.W. (1988). Dietary risk factors and their modification in cardiovascular disease. Journal of Consulting and Clinical Psychology, 56, 350-357.

Jenkins, C.D. (1983). Psychosocial and behavioral factors. In N. Kaplan \& J. Stamler (Eds.), Prevention of coronary heart disease (pp. 98-112). Philadelphia, PA: Saunders. Jenkins, C.D. (1988). Epidemiology of cardiovascular diseases. Journal of Consulting and Clinical Psychology, 56, 324-332.

Johnson, H.L., Cornoni, J.C., Cassel, J.C., Tyroler, H.A., Heyden, S., \& Hames, C.G. (1975). Influence of race, sex and weight on blood pressure behavior in young adults. American Journal of Cardiology, 35, 523-530.

Kamarck, T.W. (1992). Recent developments in the study of cardiovascular reactivity: Contributions from Psychometric Theory and social psychology. Psychophysiology, 29, 491-503.

Kannel, W.B. (1986). Epidemiologic into atherosclerotic cardiovascular disease from the Framingham Heart Study. In M.L. Pollock \& D.H. Schmidt (Eds.), Heart Disease and Rehabilitation (2nd ed., pp 3-27). New York: Wiley.

Kamarck, T.W., Jennings, J.R., Debski, T.T., Glickman-Weiss, E., Johnson, P.S., Eddy, M.J., \& Manuck, S.B. (1992). Reliable measures of behaviorally-evoked cardiovascular reactivity from a PC-based test battery: Results from student and community samples. Psychophysiology, 29, 17-28.

Kamarck, T.W., Jennings, J.R., \& Manuck, S.B. (1993 ). Psychometric applications in the assessment of cardiovascular reactivity. Homeostasis in Health and Disease, 
Kamarck, T.W., Jennings, J.R., Stewart, C.J., \& Eddy, M.J. (1993 ). Reliable responses to a cardiovascular reactivity protocol: A replication study in a bi-racial female sample. Psychophysiology, 30, 627-634.

Kasprowicz, A.L., Manuck, S.B., \& Krantz, D.S. (1988). Reproducibility of individual differences in cardiovascular response to behavioral and physiological challenge. Psychophysiology, 25, 461.

Kasprowicz, A.L., Manuck, S.B., Malkoff, S.B., \& Krantz, D.S. (1990). Individual differences in behaviorally evoked cardiovascular response: Temporal stability and hemodynamic patterning. Psychophysiology, 27, 605-619.

Kate, S.H., Hediger, M.C., Schall, J.L., Bowers, E.J., Barker, W.F., Aurand, S., Ebelith, P.B., Gruskin, A.B., \& Parks, J.S.D. (1980). Blood Pressure, growth and maturation from childhood to adolescence. Hypertension, 2, 55-69.

Krantz, D.S., Contrada, RJ, Hill, D.R., \& Friedler, E. (1988). Environmental stress and biobehavioral antecedents of coronary heart disease. Journal of Consulting and Clinical Psychology, 56, 331-341.

Keys, A., Taylor, H.L., Blackburn, H.Y., Brozek, J., Anderson, J., \& Simonson, E. (1971). Mortality and coronary heart disease among men studied for 23 years. Archives of Internal Medicine, 128, 201-214.

Krantz, D.S., Manuck, S.B., \& Wing, R.R. (1986). Psychological stressors and task variables as elicitors of reactivity. In K. Matthews, Weiss, S., Detre, T, Dembrowski, T, Falkner, B., Manuck, S.B., and Williams, R. (Eds.), Handbook of stress, reactivity, and cardiovascular disease (pp. 85-108). New York: John Wiley \& Sons. 
Lacey, J.I., Kagan, J., \& Lacey, B.C. (1963). The visceral level: Situational determinants and behavioral correlates of autonomic response patterns. In P.H. Knapp (Ed.), Expression of emotions in Man. New York: International University Press.

Lacey, J.I., \& Lacey, B.C. (1962). The law of initial value in the longitudinal study of autonomic responses and response patterns over a four year interval. Annals of the New York Academy of Science, 98, 1322-1326.

Lawler, H.A. (1980). Cardiovascular and electrodermal response patterns in heart rate reactive individuals during psychological stress. Psychophysiology, 17, 464-470.

Levy, D., \& Kannel, W.B. (1988). Cardiovascular risks: New insights from Framingham. American Heart Journal, 116, 266-272.

Light, K.C., \& Obrist, P.A. (1980). Cardiovascular response to stress: Effects of opportunity to avoid, shock experience and performance of feedback. Psychophysiology, 17, 243-252.

Light, K.C., Turner, J.R., Hinderliter, A., \& Sherwood, A. (1993). Race and gender comparisons II: Predictions of work blood pressure from laboratory baseline and cardiovascular reactivity measures. Health Psychology, 12, 366-375.

Lovallo, W. (1975). The cold pressor test and autonomic function: A review and integration. Psychophysiology, 12, 268-283.

Lovallo, W.R., Pincomb, G.A., \& Wilson, M.F. (1986). Heart rate reactivity and Type A behavior as modifiers of physiological response to active and passive coping. Psychophysiology, $\underline{23,} 105-112$.

Malmo, R.B., Shagrass, C., Davis, F.H. (1950). Symptom specificity and bodily reactions during psychiatric interview. Psychosomatic Medicine, 12, 362-376. 
Mancia, G., Casadei, R., Gropelli, A., Parati, G., \& Zanchetti, A. (1991). Effects of stress on diagnosis of hypertension. Hypertension, 17 (suppl. III), 56-62.

Manuck, S.B. (1994). Cardiovascular reactivity in cardiovascular disease: "Once more unto the breach". International Journal of Behavioral Medicine, 1, 4-31.

Manuck, S.B., \& Garland, F.N. (1980). Stability of individual differences in cardiovascular reactivity: A thirteen-month follow-up. Physiology and Behavior, 24, 621-624.

Manuck, S.B., Harvey, A.E., (1979). Effects of coping on blood pressure responses to threat of aversive stimulation. Psychophysiology, 16, 136-142.

Manuck, S.B., Kamarck, T.W., Kasprowicz, A.L., \& Waldstein, S.R. (1993). Stability and patterning of behaviorally evoked cardiovascular reactivity. In J. Blascovich \& E.S. Katkin (Eds.), Cardiovascular reactivity to psychological stress and disease (pp. 111-134). Washington, D.C.: American Psychological Association.

Manuck, S.B., Kaplan, J.R., \& Clarkson, T.B. (1983). Behaviorally-induced heart rate reactivity and atherosclerosis in cymonolgus monkeys. Psychosomatic Medicine, 45, 95-108.

Manuck, S.B., Kasprowicz, A.L., Monroe, S.M., Larkin, K.T., \& Kaplan, J.R. (1989). Psychophysiologic reactivity as a dimension of individual differences. In N. Schneiderman, S. Weiss, \& P. Kaufman, Handbook of methods and measurement in cardiovascular behavioral medicine (pp. 365 - 382). New York: Plenum Press.

Manuck, S.B., \& Krantz, D.S. (1986). Psychophysiologic reactivity in coronary heart disease and essential hypertension. In KA Matthews, S.M. Weiss, T. Detre, T.M. Dembroski, B. Falkner, S.B. Manuck, \& R.B. Williams (Eds.), Handbook of stress, reactivity and cardiovascular disease (pp. 11-34). New York: Wiley. 
Manuck, S.B., Morrison, R.L., Bellack, A.S., \& Polefrone, J.M. (1985). Behavioral factors in hypertension: Cardiovascular responsivity, anger, and social competence. In M.A. Chesney, S. Goldston, \& R. H. Rosenman (Eds.), Anger and hostility in cardiovascular and behavioral disorders (pp. 149-172). New York: Hemisphere/McGraw-Hill.

Manuck, S.B., \& Schefer, D.C. (1978). Stability of individual differences in cardiovascular response to cognitive challenge. Physiology and Behavior, 21, 675-678.

Matthews, KA, Manuck, S.B., \& Saab, P.G. (1986). Cardiovascular responses of adolescents during a naturally occurring stressor and their behavioral and psychophysiological predictors. Psychophysiology, 23, 198-209.

Matthews, KA, Rakaczky, C.J., Stoney, C.M., \& Manuck, S.B. (1987). Are cardiovascular responses to behavioral stressors a stable individual variable in childhood? Psychophysiology, 24, 464-473.

McKinney, M.E., Miner, M.H., Ruddel, H., Hcilvain, H.E., Witte, H., Buell, J.C., Eliot, R.S., \& Grant, L.B. (1985). The standardized mental stress protocol: Test-retest reliability and comparison with ambulatory blood pressure monitoring. Psychophysiology, 22, 453-463.

Melville, D.I., \& Raftery, E.B. (1980). Blood pressure changes during acute mental stress in hypertensive subjects using the Oxford intra-arterial system. Journal of Psychosomatic Research, 25, 487-497.

Myrtek, M. (1985). Adaptation effects and the stability of physiological responses to repeated testing. In A. Steptoe, H. Ruddel, \& H. Neus (Eds.), Clinical and methodological issues in cardiovascular psychophysiology. Berlin: Springer-Verlag.

Nunnally, J. (1967). Psychometric Theory. New York: McGraw-Hill. Obrist, P.A. (1981). Cardiovascular Psychophysiology. New York: Plenum. 
Obrist, P.A., Gaebelein, CJ, Teller, S.E., Langer, A.W., Grignolo, A., Light, K.C., \& McCubbin, J.A. (1978). The relationship among heart rate, carotid dP/dt and blood pressure in humans as a function of the type of stress. Psychophysiology, 15, 102-115.

Parati, G., Tarazzi, S., Ravogli, A., Casadei, R., Omboni, S., Mancia, G. (1991). Methodological problems in evaluation of cardiovascular effects of stress in humans. Hypertension, 17(Suppl. III), 50-55.

Pesonen, E., Norio, R., Hirvonen, J., Karkola, K., Kuusela, V., Laaksonen, H., Mottonen, M., Nikkari, T., Raekillia, J., \& Viikari, J. (1990). Intimal thickening in the coronary arteries of infants and children as an indicator of risk factors for coronary heart disease. European Heart Journal, 11(Suppl. E), 53-60.

Pickering, T.G. (1995, March). Reactivity as a risk factor of cardiovascular disease: The emperor has no clothes. Keynote dialogue presented at the Sixteenth Annual Convention of the Society of Behavioral Medicine, San Diego, CA.

Pickering, T.G., \& Gerin, W. (1990). Cardiovascular reactivity in the laboratory and the role of behavioral factors in hypertension: A critical review. Annals of Behavioral Medicine, 12, 3-16.

Pooling Project Research Group. (1978). Relation of blood pressure, serum cholesterol, smoking habit, relative weight and ECG abnormalities to incidence of major coronary events: Final report of the Pooling Project, Journal of Chronic Diseases, 31, 201-306.

Prineas, RJ, Gillum, R.S., Horibe, H., \& Hannan, P.J. (1980). Minneapolis Children's Blood Pressure Study. Part II: Multiple determinants of blood pressure. Hypertension, 2, 124-128. Rosenman, R.H., Brand, RJ, Jenkins, C.D., Friedman, M., Straus, \& Wurm, M. (1975). Coronary heart disease in the Western Collaborative Group Study: Final follow-up experience of 8 years. Journal of the American Medical Association, 233, 872-877. 
Sausen, K.P., Lovallo, W.R., \& Pincomb, G.A. (1992). Cardiovascular responses to occupational stress in male medical students: A paradigm for ambulatory monitoring studies. Health Psychology, 11, 55-60.

Saab, P.G., Llabre, M.M., Hurwitz, B.E., Frame, C.A., Reineke, L.J., Fins, A.I., McCalla, J., Cieply, I.K., \& Schneiderman, N. (1992). Myocardial and peripheral vascular responses to behavioral challenges and their stability in Black and White Americans. Psychophysiology, 29, 384-397.

Scheidt, S. (1996). A whirlwind tour of cardiology for the mental health professional. In R. Allan \& S. Scheidt (Eds.), Heart \&Mind: The Practice of Cardiac Psychology (pp.63-124). Washington, D.C.: American Psychological Association.

Schneiderman, N. (1995, March). Reactivity is a candidate risk factor for hypertension and coronary heart disease: Our servant is dressed modestly. Keynote dialogue presented at the Sixteenth Annual Convention of the Society of Behavioral Medicine, San Diego, CA.

Schwartz, J.L. (1987). Review and evaluation of smoking cessation methods: The United States and Canada, 1978-1985. U.S. Department of Health and Human Services. NIH Publication No. 87-2940.)

Schwartz, G.E., Weinberger, D.A., \& Singer, J.E. (1981). Cardiovascular differentiation of happiness, sadness, anger, and fear following imagery and exercise. Psychosomatic Medicine, $\underline{43,} 343-364$.

Shekelle, R.B., Gale, M., \& Norusis, M. (1985). For the aspirin myocardial infarction study group: Type A score (Jenkins Activity Survey) and risk of recurrent coronary heart disease in the aspirin myocardial infarction study. American Journal of Cardiology, 56, 221. 
Sherwood, A., Dolan, C.A., \& Light, K.C. (1990). Hemodynamics of blood pressure responses during active and passive coping. Psychophysiology, 27, 656-668.

Sherwood, A., \& Turner, J.R. (1992). A conceptual and methodological overview of cardiovascular reactivity research. In J.R. Turner, A Sherwood, \& K.C. Light (Eds.), Individual differences in cardiovascular response to stress (pp. 3-32). New York: Plenum.

Sime, W.E., Buell, J.C., \& Elliot, R.S. (1980). Cardiovascular responses to emotional stress (Quiz interview) in post-infarct cardiac patients and matched control subjects. $\underline{\text { Journal of }}$ Human Stress, 6, 39-46.

Steptoe, A. (1983). Psychological Factors in Cardiovascular Disorders. London: Academic Press.

Steptoe, A., Melville, D., \& Ross, A. (1984). Behavioral response demands, cardiovascular reactivity, and essential hypertension. Psychosomatic Medicine, 46, 33-48.

Thorndike, R.L. (1967). The analysis and selection of test items. In D.N. Jackson \& S. Messick (Eds.), Problems in human assessment (pp. 217-240). New York: McGraw-Hill.

Turner, J.R., \& Carroll, D. (1985). The relationship between laboratory and "real world" heart rate activity: An exploratory study. In J.F. Orlebake, G. Mulder, \& L.J.P. van Doornen (Eds.), Psychophysiology of cardiovascular control: Models, methods, and data (pp. 895-907). New York: Plenum.

Turner, J.R., Carroll, D., Dean, S., \& Harris, M.G. (1987). Heart rate reactions to standard laboratory challenges and a naturalistic stressor. International Journal of Psychophysiology, 5, 151-152. 
Turner, J.R., Girdler, S.S., Sherwood, A., \& Light, K.C. (1990). Cardiovascular responses to behavioral stressors: Laboratory-field generalization and inter-task consistency. Journal of Psychosomatic Research, 34, 581-589.

Turner, J.R., \& Sherwood, A. (1991). Postural effects on blood pressure reactivity: Implications for studies of laboratory-field generalization. Journal of Psychosomatic Medicine, 35, 289-295.

Turner, J.R., Ward, M.M., Gellman, M.D., Johnston, D.W., Light, K.C., \& van Doornen, L.J.P. (1994). The relationship between laboratory and ambulatory cardiovascular activity: Current evidence and future directions. Annals of Behavioral Medicine, 16, 12-23. van Doornen, L.P.J., \& van Blokland, R.W. (1992). The relationship between cardiovascular and catecholamine reactions to laboratory and real-life stress. Psychophysiology, $\underline{29,} 173-181$.

van Doornen, L.J.P., \& Turner, RJ (1992). The ecological validity of laboratory stresstesting. In J.R. Turner, A. Sherwood, \& K.C. Light (Eds.), Individual differences in cardiovascular response to stress (pp. 63-83). New York: Plenum.

Van Egeren, L.F., \& Gellman, M.D. (1992). Cardiovascular reactivity to everyday events. In E.H. Johnson, W.D. Gentry, \& S. Julius (Eds.), Personality, elevated blood pressure, and hypertension. Washington, D.C.: Hemisphere.

Van Egeren, L.F., \& Sparrow, A.W. (1989). Laboratory stress testing to assess real-life cardiovascular reactivity. Psychosomatic Medicine, 51, 1-9.

Ward, M.M., Turner, J.R., \& Johnston, D.W. (1994). Temporal stability of ambulatory cardiovascular monitoring. Annals of Behavioral Medicine, 16, 3-11. 
Warwick-Evans, L, Walker, J., \& Evans, J. (1988). A comparison of psychologicallyinduced cardiovascular reactivity in laboratory and natural environments. Journal of Psychosomatic Research, 32, 493-504.

Watson, R.D.S., Stallard, T., Flinn, R.M., \& Littler, W.A. (1980). Factors determining direct arterial pressure and its variability in hypertensive man. Hypertension, 2, 333-341.

Weinberger, D.A., Schwartz, G.E., \& Davidson, RJ (1979). Low-anxious, high-anxious and repressive coping styles: Psychometric patterns and behavioral and physiological responses to stress. Journal of Abnormal Psychology, 88, 369-380.

Williams, R.B., Bittker, T.E., Buchsbaum, M.S., \& Wynne, L.C. (1975). Cardiovascular and neurophysiologic correlates of sensory intake and rejection: I. Effect of cognitive tasks. Psychophysiology, 12, 427-433.

Wood, D.L., Sheps, S.G., Elveback, L.R., \& Shirger, A. (1984). Cold pressor test as a predictor of hypertension. Hypertension, 6, 301-306. 
Appendix A

ANOVA Summary Tables

Resting Systolic Blood Pressure Levels

\begin{tabular}{lcrllc} 
Source & Sum of Squares & \multicolumn{1}{c}{ df } & Mean Square & F & Significance \\
\hline SysRest & 79.99 & 5 & 15.99 & 1.17 & .33 \\
Error & 1431.09 & 105 & 13.63 & & \\
\hline
\end{tabular}

Resting Diastolic Blood Pressure Levels

\begin{tabular}{lcrlcc} 
Source & Sum of Squares & \multicolumn{1}{c}{ df } & Mean Square & F & Significance \\
\hline DiaRest & 61.38 & 5 & 12.27 & .96 & .45 \\
Error & 1346.55 & 105 & 12.82 & & \\
\hline
\end{tabular}

Resting Heart Rate Levels

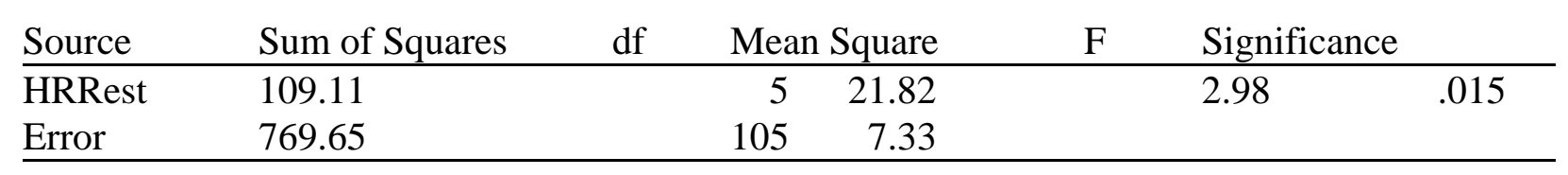


Systolic Blood Pressure Levels

Task X Period Repeated Measures ANOVA

\begin{tabular}{lcrrrr} 
Source & Sum of Squares & df & Mean Square & \multicolumn{1}{c}{ F } & Significance \\
\hline Task & 6993.29 & 5 & 1398.66 & 26.12 & .001 \\
Error (Task) & 4818.99 & 90 & 53.54 & & \\
Period & 9261.14 & 2 & 4630.57 & 180.20 & .001 \\
Error (Period) & 925.08 & 36 & 25.70 & & \\
Task X Period & 4706.69 & 10 & 470.67 & 14.20 & .001 \\
Error (Task X Period) & 5964.41 & 180 & 33.14 & & \\
\hline
\end{tabular}

Diastolic Blood Pressure Levels

Task X Period Repeated Measures ANOVA

\begin{tabular}{lcrrrr} 
Source & Sum of Squares & df & Mean Square & \multicolumn{1}{c}{ F } & \multicolumn{2}{c}{ Significance } \\
\hline Task & 2483.43 & 5 & 496.69 & 22.76 & .001 \\
Error (Task) & 1964.06 & 90 & 21.82 & & \\
Period & 4453.85 & 2 & 2226.92 & 108.68 & .001 \\
Error (Period) & 737.66 & 36 & 20.49 & & \\
Task X Period & 1538.34 & 10 & 153.83 & 8.92 & .001 \\
Error (Task X Period) & 3106.12 & 180 & 17.26 & & \\
\hline
\end{tabular}

Heart Rate Levels

Task X Period Repeated Measures ANOVA

\begin{tabular}{lcrrrr} 
Source & Sum of Squares & df & Mean Square & \multicolumn{1}{c}{ F } & Significance \\
\hline Task & 15361.59 & 5 & 3072.32 & 54.08 & .001 \\
Error (Task) & 5112.62 & 90 & 56.81 & & \\
Period & 11860.57 & 2 & 5930.28 & 157.13 & .001 \\
Error (Period) & 1358.71 & 36 & 37.74 & & .001 \\
Task X Period & 10071.71 & 10 & 1007.17 & 29.18 & \\
Error (Period X Task) & 6213.22 & 180 & 34.52 & & \\
\hline
\end{tabular}


Systolic Blood Pressure Change Scores

Repeated Measures ANOVA

\begin{tabular}{lcrrrc} 
Source & Sum of Squares & \multicolumn{1}{c}{ df } & Mean Square & F & Significance \\
\hline Systolic Change & 10283.35 & 5 & 2056.67 & 21.30 & .001 \\
Error & 9657.35 & 100 & 96.57 & & \\
\hline
\end{tabular}

Diastolic Blood Pressure Change Scores

Repeated Measures ANOVA

\begin{tabular}{lcrrcc} 
Source & Sum of Squares & \multicolumn{1}{c}{ df } & Mean Square & F & Significance \\
\hline Diastolic Change & 3486.08 & 5 & 697.22 & 14.44 & .001 \\
Error & 4828.59 & 100 & 48.29 & & \\
\hline
\end{tabular}

Heart Rate Change Scores

Repeated Measures ANOVA

\begin{tabular}{lcrrrc} 
Source & Sum of Squares & df & Mean Square & F & Significance \\
\hline Heart Rate Change & 23837.09 & 5 & 4767.42 & 49.87 & .001 \\
Error & 9559.06 & 100 & 95.59 & & \\
\hline
\end{tabular}


Systolic Blood Pressure Residualized Change Scores

Stepwise Regression Equation ANOVA

Step 1

\begin{tabular}{lccccc} 
Source & Sum of Squares & df & Mean Square & F & Significance \\
\hline HG & 2.63 & 1 & 2.63 & 2.89 & .11 \\
Residual & 17.34 & 19 & .91 & & \\
\hline
\end{tabular}

Systolic Blood Pressure Residualized Change Scores

Stepwise Regression Equation ANOVA

Step 2

\begin{tabular}{lccrcc} 
Source & Sum of Squares & df & Mean Square & F & Significance \\
\hline HG,MI & 4.23 & 2 & 2.15 & 2.47 & .11 \\
Residual & 15.68 & 18 & .87 & & \\
\hline
\end{tabular}

Systolic Blood Pressure Residualized Change Scores

Stepwise Regression Equation ANOVA

Step 3

\begin{tabular}{lccrcc} 
Source & Sum of Squares & df & Mean Square & F & Significance \\
\hline HG,MI,MO & 4.35 & 3 & 1.45 & 1.58 & .23 \\
Residual & 15.62 & 17 & .92 & & \\
\hline
\end{tabular}

Systolic Blood Pressure Residualized Change Scores

Stepwise Regression Equation ANOVA

Step 4

\begin{tabular}{lccccc} 
Source & Sum of Squares & df & Mean Square & F & Significance \\
\hline HG,MI,MO,SP & 4.58 & 4 & 1.15 & 1.19 & .35 \\
Residual & 15.39 & 16 & .96 & & \\
\hline
\end{tabular}

Systolic Blood Pressure Residualized Change Scores

Stepwise Regression Equation ANOVA

Step 5

\begin{tabular}{lccccc} 
Source & Sum of Squares & df & Mean Square & F & Significance \\
\hline HG,MI,MO,SP,MA & 4.59 & 5 & .92 & .90 & .51 \\
Residual & 15.38 & 15 & 1.03 & & \\
\hline
\end{tabular}


Diastolic Blood Pressure Residualized Change Scores

Stepwise Regression Equation ANOVA

Step 1

\begin{tabular}{lccccc} 
Source & Sum of Squares & df & Mean Square & F & Significance \\
\hline HG & .80 & 1 & .80 & .79 & .38 \\
Residual & 19.19 & 19 & 1.01 & & \\
\hline
\end{tabular}

Systolic Blood Pressure Residualized Change Scores

Stepwise Regression Equation ANOVA Step 2

\begin{tabular}{lccccc} 
Source & Sum of Squares & df & Mean Square & F & Significance \\
\hline HG,MO & 1.32 & 2 & .66 & .64 & .54 \\
Residual & 18.68 & 18 & 1.04 & & \\
\hline
\end{tabular}

Systolic Blood Pressure Residualized Change Scores

Stepwise Regression Equation ANOVA

Step 3

\begin{tabular}{lccccc} 
Source & Sum of Squares & df & Mean Square & F & Significance \\
\hline HG,MI,SP & 1.36 & 3 & .45 & .41 & .74 \\
Residual & 18.63 & 17 & 1.10 & & \\
\hline
\end{tabular}

Systolic Blood Pressure Residualized Change Scores

Stepwise Regression Equation ANOVA

\section{Step 4}

\begin{tabular}{lccccc} 
Source & Sum of Squares & df & Mean Square & F & Significance \\
\hline HG,MI,SP,MO & 1.71 & 4 & .43 & .37 & .82 \\
Residual & 18.28 & 16 & 1.14 & & \\
\hline
\end{tabular}

Systolic Blood Pressure Residualized Change Scores

Stepwise Regression Equation ANOVA

Step 5

\begin{tabular}{lccccc} 
Source & Sum of Squares & df & Mean Square & F & Significance \\
\hline HG,MI,SP,MO,MA & 1.80 & 5 & .36 & .30 & .91 \\
Residual & 18.20 & 15 & 1.21 & & \\
\hline
\end{tabular}


Heart Rate Residualized Change Scores

Stepwise Regression Equation ANOVA

Step 1

\begin{tabular}{lccccc} 
Source & Sum of Squares & df & Mean Square & F & Significance \\
\hline MO & 5.01 & 1 & 5.01 & 7.09 & .015 \\
Residual & 13.44 & 19 & .71 & & \\
\hline
\end{tabular}

Heart Rate Residualized Change Scores

Stepwise Regression Equation ANOVA

Step 2

\begin{tabular}{lccccc} 
Source & Sum of Squares & df & Mean Square & F & Significance \\
\hline MO,MI & 9.06 & 2 & 4.53 & 8.69 & .002 \\
Residual & 9.39 & 18 & .52 & & \\
\hline
\end{tabular}

Heart Rate Residualized Change Scores

Stepwise Regression Equation ANOVA

Step 3

\begin{tabular}{lccccc} 
Source & Sum of Squares & df & Mean Square & F & Significance \\
\hline MO,MI,SP & 12.12 & 3 & 4.04 & 9.23 & .0006 \\
Residual & 7.88 & 18 & .43 & & \\
\hline
\end{tabular}

Heart Rate Residualized Change Scores

Stepwise Regression Equation ANOVA

Step 4

\begin{tabular}{lccccc} 
Source & Sum of Squares & df & Mean Square & F & Significance \\
\hline MO,MI,SP,HG & 11.15 & 4 & 2.79 & 6.11 & .0035 \\
Residual & 7.30 & 16 & .46 & & \\
\hline
\end{tabular}

Heart Rate Residualized Change Scores

Stepwise Regression Equation ANOVA

Step 5

\begin{tabular}{lccccc} 
Source & Sum of Squares & df & Mean Square & F & Significance \\
\hline MO,MI,SP,HG,MA & 11.23 & 5 & 2.25 & 4.67 & .009 \\
Residual & 7.22 & 15 & .48 & & \\
\hline
\end{tabular}


Appendix B

Telephone Screening Form

1) Are you currently taking any of the following on a regular basis:

\begin{tabular}{|c|c|}
\hline amphetamines... & Yes \\
\hline diet pills......................... & Yes \\
\hline cold or allergy medicine......... & Yes \\
\hline asthma medication (sympathomimetics)............... & Yes \\
\hline Beta-Blockers (e.g., Inderal, Tenormin)............... & Yes \\
\hline Psychoactive (e.g., Xanax, Haldol, Lithium)........ & Yes \\
\hline Heart medication (nitroglycerin, Coumadin).......... & Yes \\
\hline
\end{tabular}

Please explain all "Yes" responses (amount, frequency, duration):

2) Have you ever received medical treatment for any of the following:

Diabetes............................................................................ Yes

Hypertension......................................................................... Yes No

Coronary Heart Disease (e.g., heart attack, unstable angina)......... Yes No

Other Chronic or Severe Medical Problems.................................... Yes No

If yes, please describe: 
Appendix C

$\underline{\text { Pre-assessment Screening Form }}$

1) Have you taken any of the following substances in the past 24 hours:

\begin{tabular}{|c|c|}
\hline amphetamines.. & Yes \\
\hline diet pills...... & Yes \\
\hline 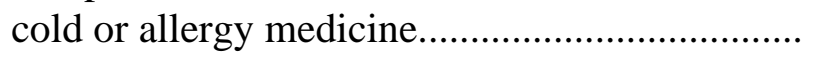 & Yes \\
\hline asthma medication (sympathomimetics).............. & Yes \\
\hline Beta-Blockers (e.g., Inderal, Tenormin)............... & Yes \\
\hline Psychoactive (e.g., Xanax, Haldol, Lithium)........ & Yes \\
\hline Heart medication (nitroglycerin, Coumadin)......... & Yes \\
\hline
\end{tabular}

Please explain all "Yes" responses:

2) In the past three hours have you used any of the following:

Alcohol products (e.g., beer, wine, liquor, cough medication......... Yes No

Caffeine-containing products (soft-drinks, coffee, No-Doze)......... Yes No

Please explain all "Yes" responses:

3) In the past one hour have you used any of the following tobacco products:

$\begin{array}{lll}\text { Cigarettes....................... } & \text { Yes } & \text { No } \\ \text { Cigars.............................. } & \text { Yes } & \text { No } \\ \text { Chewing Tobacco ............. } & \text { Yes } & \text { No }\end{array}$

Please explain all "Yes" responses:

4) Have you taken any over-the-counter medications in the past 24 hours: Yes No If yes, pleases describe:

5) Have you exercised within the past hour

Yes

No

If yes, please describe: 


\section{Appendix D}

\section{$\underline{\text { Laboratory Procedure Time-Line }}$}

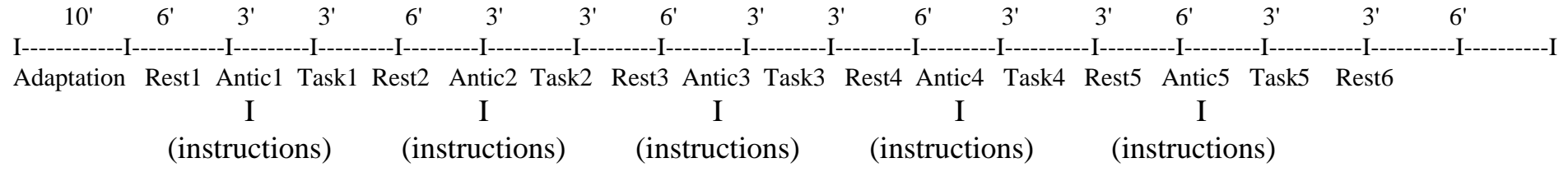

Ambulatory Procedure Time-Line

$\begin{array}{ccc}3^{\prime} & 3^{\prime} \\ \text { I--------I } & \left(30-45^{\prime} \text { break }\right) & \text { I--------I } \\ \text { Anticip } & & \text { Nat1 }\end{array}$




\section{CURRICULUM VITAE}

\section{JAMES P. DAVIG, Ph.D.}

Home Address

Work Address

\section{Education}

32 Berna Boulevard

Wabasha, MN 55988

St. Elizabeth's Mental Health Clinic

224 Alleghany Avenue

Wabasha, MN 55981

(651) 565-2678

email: stejdavig@wabasha.net

B.A. 1985, Concordia College, Moorhead, Minnesota 56562

Major: Psychology

M.S. $\quad$ 1990, North Dakota State University, Fargo, North Dakota 58105

Clinical Psychology Program

Advisor: Patrick Edwards, Ph.D.

Thesis Title: The Effects of Family Pain Models on the Expectation and Experience of a Painful Stimulus

Patrick Edwards, Ph.D. (Chairperson)

Ph.D. May 1999, West Virginia University, Morgantown, WV 26505

Adult Clinical Psychology Program (APA Approved)

Advisor: Kevin T. Larkin, Ph.D.

Dissertation Title: Generalizability of Cardiovascular Reactivity to Stress Among

Doctoral Students Between Laboratory and Natural Settings

Dissertation Committee: Kevin Larkin, Ph.D. (Chairperson), Barry Edelstein, Ph.D., Alfred Kasprowicz, Ph.D., Stanley Cohen, Ph.D., LauraLee Sherwood, DVM

\section{Pre-Doctoral Internship}

August 15, 1996 - August 14, 1997

University of Mississippi/Jackson VA Medical Center Psychology Residency Consortium, Jackson, MS (APA Approved)

\section{Current Position}

August 18, 1997 - Present

St. Elizabeth's Mental Health Clinic, Wabasha, MN

Duties include provision of psychological assessment and behavioral intervention within a primary care clinic; inservice presentations to allied health care professionals; and educational and screening programs to the general public. 


\section{Previous Clinical Experience}

May 15, 1997 - August 14, 1997

Psychology Resident, Head Pain Service, University of Mississippi Medical Center, Jackson, MS Supervisor: Donald Penzien, Ph.D.

Clinical duties included: assessment and provision of cognitive-behavioral treatment to patients with chronic head pain. Research activities included investigation into, and presentation of research findings related to headache precipitants and associated pain behaviors as reported by chronic head pain patients.

February 15, 1997 - May 14, 1997

Psychology Resident, Neuropsychology Service, University of Mississippi Medical Center, Jackson, MS Supervisor: Bradley Burton, Ph.D.

Clinical duties included provision of neuropsychological assessment and recommendations involving outpatients, as well inpatients with both acute cognitive dysfunction and those undergoing longterm rehabilitation.

November 15, 1996 - February 14, 1997

Psychology Resident, Health Behavior Program, Jackson VA Medical Center, Jackson, MS Supervisor: Thomas J. Payne, Ph.D.

Clinical duties include: assessment and provision of treatment recommendations for primary care and cardiac rehabilitation patients; assistance with the Smoking Cessation Program (assessment, individual and group treatment); provision of individual psychotherapy (cognitive-behavioral in nature). Education: involvement in Jackson VA Medical Center Psychology Section case presentations, and University of Mississippi Medical Center Department of Psychology Research Rounds.

August 15, 1996 - November 14, 1996

Psychology Resident, Eating Disorder Service, University of Mississippi Medical Center, Jackson, MS

Supervisor: William G. Johnson, Ph.D.

Clinical duties included: assessment and treatment of adult and adolescent outpatients seeking treatment for eating disorders and weight management. Treatment was behavioral in nature, and involved individual and group formats. Research involvement included investigation of the development of maladaptive weight control behaviors among adolescents, and identification of behavioral and cognitive factors employed in defining binge behavior. Education/outreach efforts included assisting in organizing two educational/training seminars for local school counselors, and assistance in developing an eating disorder support group at a local church.

April 1996 - June 1996 (8 hours/week)

Doctoral Practicum Student, Hopemont Psychiatric Hospital, Terra Alta, WV

Supervisor: Barry Edelstein, Ph.D.

Duties primarily included cognitive and functional evaluations of long-term care psychiatric residents, and generation of detailed evaluations with recommendations for improving or maintaining resident's levels of adaptive functioning. 
August 1995 - March 1995 (16 hours/week)

Doctoral Practicum Student, Monongalia Psychological Services, Morgantown, WV 26505

Supervisor: Lydia McClarnon, Ph.D.

Duties included the evaluation and treatment of patients with chronic pain disorders referred from a local pain management center, including pre-surgical psychological assessments to assist in the determination of the appropriateness of surgical and psychological intervention.

November 1993 - August 1996 (8 hours/week)

Psychological Consultant, West Virginia Department of Corrections, Industrial, WV 26375

Supervisor: Joseph Shaver, Ed.D.

Responsibilities included evaluation of minors committed to the West Virginia Industrial Home

for Youth, under the supervision of a licensed psychologist, including generation of a

psychological evaluation and placement recommendations based on clinical interview,

psychological testing (intellectual, academic, personality), and court records.

August 1994 - August 1995 (20 hours/week)

Doctoral Practicum Student, Eating Disorder Service, Chestnut Ridge Hospital, Morgantown, WV 26505.

Supervisors: Richard J. Seime, Ph.D., Alfred L. Kasprowicz, Ph.D.

Primary duties included assessment and treatment of adult and adolescent patients with eating disorders on an inpatient and outpatient basis.

July - August 1994 (20 hours/week)

Doctoral Practicum Student, Anxiety Disorder Service, Chestnut Ridge Hospital, Morgantown, WV 26505. Supervisor: Virginia Goetsch, Ph.D.

Primary duties included assessment and treatment of anxiety disorder outpatients and group therapy focusing on stress management skills with psychiatric inpatients.

August 1993 - May 1994 (20 hours/week)

Doctoral Practicum Student, Carruth Center for Counseling and Psychological Services, West

Virginia University, Morgantown, WV 26505.

Supervisor: Phil Comer, Ph.D.

Primary duties included assessment and treatment (individual and group) of university students under the supervision of doctoral level psychologists.

July 1988 - August 1993 (40 hours/week)

Psychology Assistant/Behavioral Medicine Therapist, Section of Psychology, W-11B, Mayo

Clinic, Rochester, MN 55905.

Supervisors: Donald Williams, Ph.D., Michelle Taylor, Ph.D., Barbara Bruce, Ph.D., Peter Hauri, Ph.D., and Robert Colligan, Ph.D.

Duties included assessment and treatment of medical and psychiatric patients (in- and outpatient), and participation in educational and research activities. Treatment was behavioral in nature. Psychiatric conditions commonly treated included anxiety, somatoform, mood, and adjustment disorders. Medical conditions frequently treated included headache, obesity, irritable bowel syndrome, fibromyalgia, and nocturnal enuresis. 
September 1985 - August 1986 (40 hours/week)

Residential Living Trainer, Friendship Village, Fargo, ND 58102.

Supervisors: Ms. Ann Rau, Mr. Norlan Van Gorp

Primary duties included supervision of residential/social activities and development and implementation of behavior programs for adults with mental retardation living in an intermediate care facility.

\section{Professional Affiliations}

Association for Advancement of Behavior Therapy

Society of Behavioral Medicine

Association for Behavior Analysis

\section{Grants}

1998 Ministry Health Corporation Grant $(\$ 15,000)$

Provides funding for tobacco cessation and education programming to adults and juveniles within the service area of St. Elizabeth's Hospital

1996 West Virginia University Department of Psychology Alumni Fund Research Grant (\$250).

1996 West Virginia University Office of Academic Affairs and Research Doctoral Student Research Program Grant (\$550).

\section{Publications}

Williams, D.E., Raczynski, J.M., Domino, J., \& Davig, J.P. (1993). Psychophysiological and MMPI Personality Assessment of Headaches: An Integrative Approach. Headache, 33, 149-154.

Johnson, W.G., Boutelle, K.N., Torgrud, L., Davig, J.P., \& Turner, S. (In press). What is a Binge? The influence of Amount, Duration, and Loss of Control Criteria on Judgments of Binge Eating. International Journal of Eating Disorders.

\section{Papers and Presentations}

Davig, J.P., Larkin, K.T., \& Goodie, J. (1999, March). Does cardiovascular reactivity to stress measured in the laboratory generalize to thesis and dissertation meetings? Poster presented at the 20th Annual Meeting of the Society of Behavioral Medicine, San Diego, CA.

Boutelle, K.N., Torgrud, L., Smith, A., Davig, J.P., \& Turner, S., \& Johnson, W.G. (1997, November). Judgments of Binge Episodes: Implications for Diagnostic Criteria for Binge Eating. Poster presented at the 31st Annual Convention of the Association for Advancement of Behavior Therapy, Miami Beach, FL. 
Davig, J.P., Rains, J.C., Hotovy, L.A., \& Penzien, D.B. (1997, June). Examination of Headache Precipitants and Pain Behaviors: A Replication and Extension. Poster presented at the 39th Annual Scientific Meeting of the American Association for the Study of Headache, New York.

Hotovy, L.A., Penzien, D.B., Davig, J.P., \& Rains, J.C. (1997, June). Gynecologic Problems and Chronic Headache. Poster presented at the 39th Annual Scientific Meeting of the American Association for the Study of Headache, New York.

Davig, J.P., Larkin, K.T., \& Goodie, J. (1996, November). Does cardiovascular reactivity to stress measured in the laboratory generalize to thesis and dissertation meetings?: A preliminary investigation. Poster presented at the 30th Annual Convention of the Association for Advancement of Behavior Therapy, New York, NY.

Forsyth, J.P., Chase, P.N., Schauss, S.L., Masia, C.L., \& Davig, J.P. (1995, May). A behavior analytic reformulation of attribution theory: The naive observer's functional analysis in a social-verbal context. Paper presented at the 21st Annual Convention of the Association for Behavioral Analysis, Washington, D.C.

Masia, C.L., Chase, P.N., Forsyth, J.P., Davig, J.P., \& Schauss, S.L. (1995, May). Vicarious learning revisitied: A contemporary behavior analytic interpretation. Paper presented at the 21st Annual Convention of the Association for Behavior Analysis, Washington, D.C.

Schauss, S.L., Chase, P.N., Davig, J.P., Forsyth, J.P., \& Masia, C.L. (1995, May). More change for a buck and other (re-) interpretations of cognitive disonance. Paper presented at the 21st Annual Convention of the Association for Behavior Analysis, Washington, D.C.

Thompson, R.N., Davig, J.P., Forsyth, J.P, and Eifert, G.H. (1994, November). Prevalence and significance of cardiophobic and generalized illness fears as a function of parental medical history. Poster presented at the 28th Annual Convention of the Association for the Advancement of Behavior Therapy, San Diego, CA.

Davig, J.P., Taylor, M.L., \& Schauss, S.L. (1993, March). SCL-90-R profiles of noncardiac chest pain patients and panic disorder patients. Poster presented at the Anxiety Disorders Association of America 13th National Conference, Charleston, S.C.

Taylor, M.L., Davig, J.P., Schauss, S.L. (1993, March). A cognitive-behavioral treatment approach to noncardiac chest pain. Poster presented at the Anxiety Disorders Association of America 13th National Conference, Charleston, S.C.

Williams, D.E., Davig, J.P., \& Schauss, S.L. (1993, March). The SCL-90-R: Guidelines and normative data for its use as a screening instrument for medical patients. Poster presented at the 14th Annual Meeting of the Society of Behavioral Medicine, San Francisco, CA. 
Williams, D.E., Schauss, S.L., \& Davig, J.P. (1992, November). Integrating personality and behavior therapy: Contrasting cases of complicated bereavement. Poster presented at the 26th Annual Convention of the Association for the Advancement of Behavior Therapy, Boston, MA.

Kennedy, F.P., Allison, T., Prissel, R., Snuggerud, J.R., Davig, J.P., \& Williams, D.E. (1992, September). Identification of positive predictors for successful weight reduction during a behaviorally-based treatment program for moderate obesity. Poster presented at the North American Association for the Study of Obesity Annual Meeting, Atlanta, GA.

Davig, J.P. \& Schauss, S.L. (1992, April). Theoretical and practical issues in cognitivebehavioral treatment of irritable bowel syndrome. Symposium presented at the Midwest Association of Behavior Analysis and Therapy Spring Conference, Mankato, MN.

Williams, D.E., Davig, J.P., Schauss, S.L. (1992, March). SCL-90-R pattern specificity in headache patients: A preliminary description. Poster presented at the 13th Annual Meeting of the Society of Behavioral Medicine, New York, NY.

Davig, J.P., Schauss, S.L, \& Williams, D.E. (1991, November). A practical model for the treatment of anxiety in ventilator-dependent patients. Poster presented at the 25 th Annual Convention of the Association for the Advancement of Behavior Therapy, New York, NY.

Davig, J.P. \& Snuggerud, J.R. (1991, April). The behavioral management of obesity. Symposium presented at the Minnesota Association for Behavior Analysis Spring Conference, Mankato, MN.

Schauss, S.L., Davig, J.P., Williams, D.E., Snuggerud, J.R., \& Taylor M.L. (1991, March). Outpatient medical and psychiatric norms for the SCL-90-R: Preliminary results. Paper presented at the 12th Annual Meeting of the Society of Behavioral Medicine, Washington, DC.

Davig, J.P., Schauss, S.L., Williams, D.E., Snuggerud, J.R., \& Taylor M.L. (1991, March). Preliminary normative values for the SCL-90-R in specific outpatient behavioral medicine populations. Poster presented at the 12th Annual Meeting of the Society of Behavioral Medicine, Washington, DC.

Williams, D.E., Davig, J.P., Erfanian, N., Kvale, S., \& Schauss, S.L. (1990, November). Behavioral Medicine at the Mayo Clinic: Overview and clinical case studies. Symposium presented at the Minnesota Association for Behavior Analysis Fall Conference, Minneapolis, MN.

Davig, J.P. \& Edwards, P.W. (1990, March). The effects of family pain models on the expectation and experience of a painful stimulus. Poster presented at the 11th Annual Meeting of the Society of Behavioral Medicine, Chicago, IL. 


\section{Editorial Experience}

Ad Hoc reviewer for Behavior Therapy (1994)

Ad Hoc reviewer for Psychosomatic Medicine (1996)

Awards

(June, 1997) The American Association for the Study of Headache Resident/Fellow Travel Program Award - Outstanding Paper Designation. 